\title{
Lepidosina, a new genus of New World Limosininae (Diptera: Sphaeroceridae)
}

\author{
Stephen A. MARSHALL, Matthias BUCK and Owen LONSDALE \\ Department of Environmental Biology, University of Guelph, Guelph, Ontario N1G 2W1, Canada; \\ e-mails: samarsha@uoguelph.ca, mbuck@uoguelph.ca
}

Key words. Lepidosina, Sphaeroceridae, new genus, phylogeny, key, sexual dimorphism, New World, new species

\begin{abstract}
The New World genus Lepidosina Marshall \& Buck gen. n. is described including nine new and two previously described species: L. angusticercus Marshall \& Buck sp. n. (Caribbean, Central and South America), L. argentinensis Marshall \& Buck sp. n. (Argentina), L. cubensis Marshall \& Buck sp. n. (Cuba), L. evanescens Marshall \& Buck sp. n. (Central and South America), L. gibba (Spuler) comb. n. (Florida, Caribbean), L. inaequalis (Malloch) comb. n. (southern U.S.A., Central America, Venezuela), L. multispinulosa Marshall \& Buck sp. n. (Ecuador, Peru), L. platessa Marshall \& Buck sp. n. (Bolivia), L. proxineura Marshall \& Buck sp. n. (Brazil), L. quadrisquamosa Marshall \& Buck sp. n. (Venezuela), and L. rutricauda Marshall \& Buck sp. n. (Colombia to Peru). Keys to males and females are provided, and the species level phylogeny is analyzed based on a matrix of 24 morphological characters. The sister group of this well-defined, highly apomorphic genus remains unknown. Most species are restricted to lowland habitats. Larvae and puparia of Lepidosina remain unknown.
\end{abstract}

\section{INTRODUCTION}

The subfamily Limosininae, separated from other Sphaeroceridae by distinctive wing venation with foldlike or absent last sector of vein $\mathrm{M}$ and absent crossvein $\mathrm{bm}-\mathrm{cu}$, is distributed worldwide with high diversity in the neotropics. Many genera of Neotropical Limosininae remain to be described or revised, and the large proportion of newly described species in recent revisions (e.g., 52 out of 54 species in Robustagramma Marshall \& Cui, 2005) suggests that most Neotropical sphaerocerid species are still undescribed. The new genus described here includes two described species (Leptocera inaequalis Malloch, 1914 and Leptocera gibba Spuler, 1925) and nine other New World species described as new below. These species form a distinctive group characterized by three pairs of dorsocentral bristles, fully fused and symmetrical male sternites 6-8, reduced hypandrium, compact phallic complex with basiphallus flat against all or most of the posterodorsal surface of the distiphallus, weakly sclerotized translucent postgonites, female cercus fused with tergite 10 , and female cercus upturned with paired, apical, dorsoventrally flattened bristles. Most species are further characterized by a broad anterodorsal apodeme arising from synsternite 6-8, and by sexually dimorphic legs with swollen and distally emarginate male fore tibia, flattened male fore tarsus, ventrally flattened and curved male mid tibia without midventral bristle but with shortened ventroapical bristle accompanied by 1-2 hair-like bristles, ventrally flattened male hind tibia, and swollen male hind tarsomere 2. Several species, including the type, also have distinctive, large, flattened, scale-like bristles on male sternite 5 and/or the epandrium.

\section{MATERIAL AND METHODS}

Morphological terminology follows McAlpine (1981), with some changes as outlined in Marshall \& Langstaff (1998). Size is given as a range between the smallest and largest specimens in the material examined. Parsimony analysis of the character matrix was performed with PAUP* $4.0 \mathrm{~b} 10$ for Windows (Swofford, 2001) using the "branch and bound" algorithm.

Most specimens were collected using sweep nets, pan traps, or Malaise traps. Recently collected specimens were dried in a critical point drier after a period of storage in alcohol, but some older material is air-dried and abdominal characters are therefore difficult to see. Most specimens examined are in the University of Guelph Insect Collection.

\section{COI sequencing}

As an additional possible means for future diagnosis of Lepidosina species the "barcode" region of the mitochondrial cytochrome c oxidase I gene (COI) was sequenced for a few exemplar specimens of six sufficiently common species: L. angus-

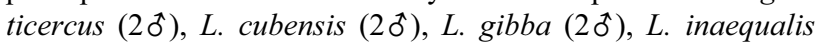

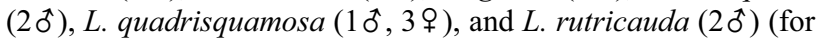
complete specimen data see material examined section under each species). Sequences were amplified using LepF1 and LepR1 primers according to the methodology described in Smith et al. (2006). Sequence data are deposited in GenBank (www.ncbi.nlm.nih.gov). Specimens are labelled with yellow "Barcode of Life" voucher labels indicating the unique specimen identifier ("DEBU $\{+4$ digits $\}$ ”).

\section{Acronyms of depositories}

AMNH - American Museum of Natural History, New York, New York, U.S.A.; ANSP - Academy of Natural Sciences, Department of Entomology, Philadelphia, Pennsylvania, U.S.A.; CASC - California Academy of Sciences, San Francisco, California, U.S.A.; CMNH - Carnegie Museum of Natural History, Pittsburgh, Pennsylvania, U.S.A.; CNCI - Canadian National Collection of Insects, Ottawa, Ontario, Canada; COEB - Centro Oriental de Ecosistemas y Biodiversidad (BIOECO), Santiago, Cuba; DEBU - Department of Environmental Biology, University of Guelph, Guelph, Ontario, Canada; EMEC - Essig Museum of Entomology, Department of Entomological Sciences, University of California, Berkeley, California, U.S.A.; INBC - Instituto Nacional de Biodiversidad, Santo Domingo de Heredia, Costa Rica; IZAV - Universidad Central de 

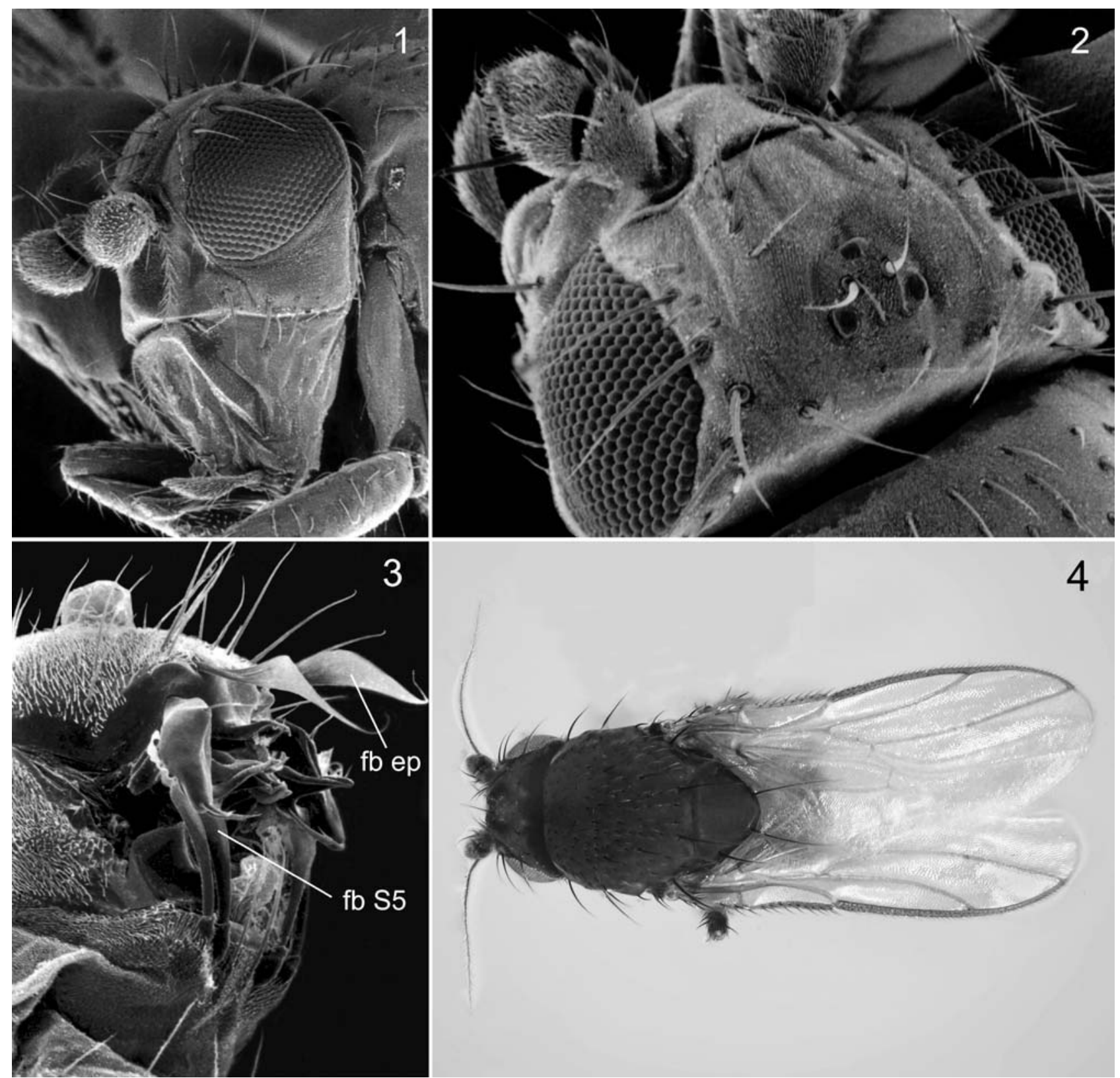

Figs 1-4. Lepidosina external features. L. gibba (Spuler), male: 1 - head, left lateral; 2 - ditto, dorsal; 3 - terminalia, left lateral; 4 - habitus, dorsal. fb ep - flattened, scale-like bristle of epandrium, fb S5 - ditto, sternite 5.

Venezuela, Maracay, Venezuela; MZSP - Museu de Zoologia da Universidade de São Paulo, São Paulo, Brazil; QCAZ - Universidad Católica del Ecuador, Quito, Ecuador; ROME - Royal Ontario Museum, Toronto, Ontario, Canada; SEMC - Snow Entomological Museum, University of Kansas, Lawrence, Kansas, U.S.A.; USNM - United States National Museum of Natural History, Smithsonian Institution, Washington, D.C., U.S.A.; ZMUC - Zoological Museum, Department of Entomology, University of Copenhagen, Copenhagen, Denmark.

\section{Genus Lepidosina Marshall \& Buck, gen. n.}

Type species: Leptocera (Scotophilella) gibba Spuler, 1925.

Etymology. Lepido- refers to the highly distinctive flattened scale-like bristles on male abdomen of many species; -sina is a common ending of generic names in the subfamily Limosininae. Gender: Feminine.

\section{Generic description}

Body length less than $2 \mathrm{~mm}$ (usually $1.2-1.5 \mathrm{~mm}$ ). Body medium to dark brown with extensive silvery pollinosity.

Head (Figs 1, 2). Frons often velvety black with contrasting silvery areas around bristle bases and between postocellar and postvertical bristles. Head chaetotaxy complete; interfrontal bristles in 3-4 pairs in addition to 2-3 small lower setulae, upper or middle two long and subequal; orbital bristles in two strong pairs; orbital setulae strong, lateroreclinate, in at least two large pairs, with upper one positioned between orbital bristles; inner vertical bristle in line with orbital bristles and larger than upper orbital; postvertical bristles small but strong, cruciate; lateroproclinate postocellar bristles present but weak; 

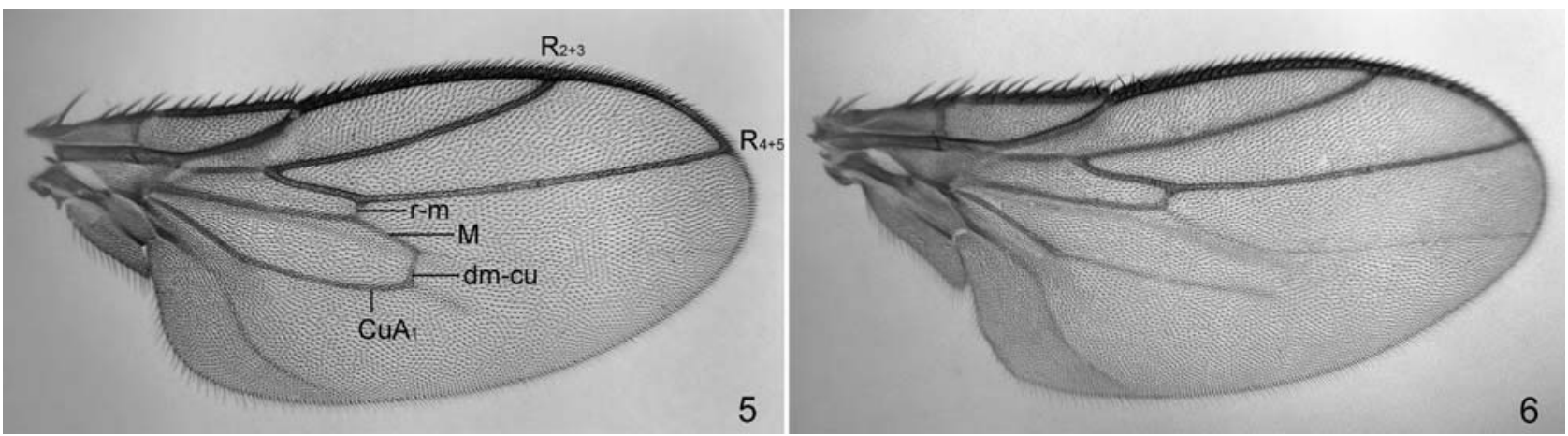

Figs 5 and 6. Lepidosina wings. 5 - L. rutricauda sp. n.; 6 - L. evanescens sp. n.

inner occipital bristles strong and cruciate or almost cruciate; outer occipital bristles small and crossing base of large outer vertical bristle. Lunule wide, face with a very broad central ridge dorsally produced into a moderately developed facial tubercle between antennae, lower margin prominent with middle part flat. Clypeus exposed as a short strip. Palpus with a long apicoventral bristle and a shorter preapical ventral bristle. Vibrissa and anterior upturned genal bristle large (latter $3 / 4$ to nearly as long as vibrissa, rarely only half as long); marginal genal bristles and subvibrissa smaller but well-developed. First flagellomere short and broad, arista dorsoapical, long-haired (hairs over $5 \times$ basal width of arista), slightly longer than head height.

Thorax. Postpronotum with a short anterior bristle and a very long posterior bristle. Notopleuron with a long bristle at anterior margin (level with an equally long supra-alar) and a smaller posterior bristle. Dorsocentral bristles in three strong pairs $(1+2)$ of ascending size (Fig. 4), prescutellar (largest) pair longer than scutellum; acrostichal setulae long, in 6-8 rows between anterior dorsocentral bristles, prescutellar pair enlarged; anterior postalar bristle very long, usually meeting or exceeding apex of scutellum. Scutellum with four marginal bristles. Katepisternal bristles very small, anterior bristle absent or setula-like, posterior bristle barely reaching anepimeron.

Legs (Figs 7-9). Fore femur with one or two long dorsal to posterodorsal bristles near middle. Fore tibia of males usually strongly excavated anterodorsally on distal half (Fig. 7) (except in L. evanescens); fore tibial excavation of all species except $L$. evanescens with pale flat setulae basally. Fore tarsus of male broad; strikingly flat in most species (Fig. 7). Mid femur of male sometimes with several strong antero- and posteroventral bristles near base. Mid tibia of male usually bowed ventrally (Fig. 9), with shortened apicoventral bristle (except in $L$. platessa); 1-2 most apical bristles of anteroventral row closely appressed to apicoventral (under low magnification often appearing as one bristle), these bristles thin, hair-like and much longer than apicoventral; ventral surface with (Fig. 8) or without rows of small ventral bristles, bristles of posteroventral row becoming stouter and larger towards tibial apex in several species (Figs 8, 9). Mid tibia of known females straight, with long midventral and apicoventral bristles. Dorsal surface of mid tibia with three evenly spaced anterodorsals (middle anterodorsal sometimes reduced or absent in males only); one small proximal posterodorsal bristle and one large distal dorsal to posterodorsal bristle, distal bristles much the largest. Tarsomeres 1 and 2 of hind leg swollen, tarsomere 2 usually more swollen in male than in female (relatively slender in both sexes of $L$. evanescens and $L$. platessa), 1.5-3 times as long as tarsomere 1, often as long as tarsomeres 3-5 combined.

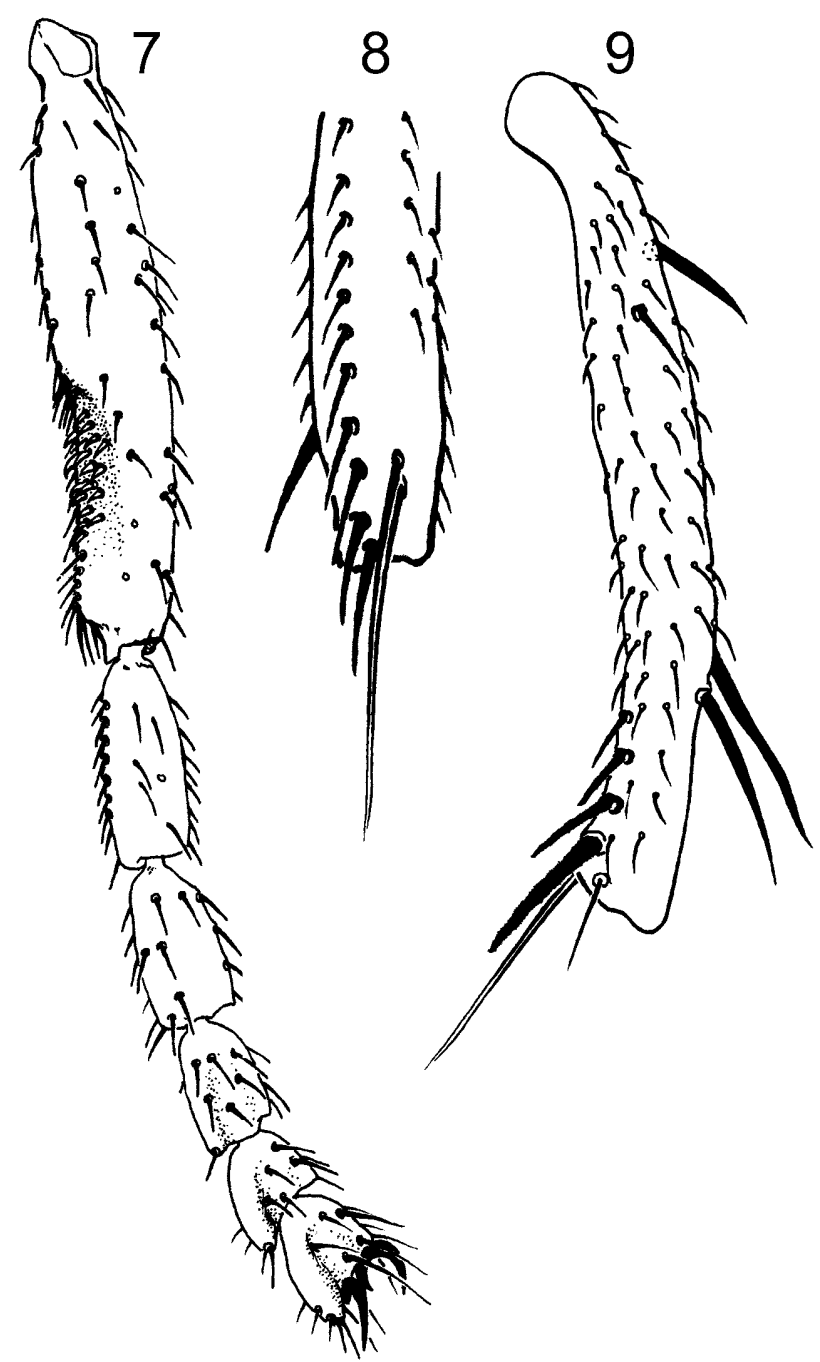

Figs 7-9. Lepidosina angusticercus sp. n., male: 7 - left fore tibia and tarsus, dorsal; 8 - apex of left mid tibia, ventral; 9 left mid tibia, posterior. 
Wing (Figs 5, 6) narrow; alula small, narrow and tapered to narrow and parallel-sided, with apex narrowly rounded to pointed. Costa ending at end of $\mathrm{R}_{4+5}$, third costal sector shorter than second. $\mathrm{R}_{2+3}$ slightly curved forward, especially near apex. $\mathrm{R}_{4+5}$ almost straight, ending well before wing tip. Veins often pale. Discal cell usually closed but in some species dm-cu, penultimate sector of $\mathrm{M}$ and $\mathrm{CuA}_{1}$ beyond bend weak or absent (Fig. 6).

Abdomen. Syntergite $1+2$ with a broad, anteromedial pale area reaching from about half way to almost to hind margin of tergite.

Male terminalia. Sternite 5 either simple or with four large, flattened, scale-like bristles at posterior margin (Fig. 3). Synsternite 6-8 symmetrical (except sometimes ventral portion that lies in genital pouch), usually forming a complete ring (ventrally open in L. platessa and $L$. multispinulosa), usually with a broad anterodorsal apodeme extending under tergite 5 or tergites 4-5 (Fig. 11); ventral portion narrow and sometimes specifically modified. Genital pouch (venter of segments 6-8) often with a separate accessory sclerite of uncertain origin (Fig. 16), and with a ring-shaped sclerite (modified, non-functional, right spiracle 7?). Epandrium small, symmetrical in both posterior and anterior view, with only small setulae; subanal plate extensive, with cerci strongly projecting ventrally as a species-specific plate or pair of lobes. Surstylus of variable shape, articulated to epandrium, sometimes with strong bristles. Subepandrial sclerite inconspicuous, where observed developed as a simple arch connecting bases of surstyli on each side. Hypandrium represented by a more or less transverse sclerite, laterally separate from epandrium; medial portion often close to phallapodeme and usually with a shallow dorsal emargination accommodating latter (Fig. 26), anterior apodeme absent or short-triangular (Fig. 64). Pregonites absent. Postgonites (Fig. 17) usually rather short and broad, bare and weakly sclerotized (more or less translucent and often hard to discern), with dorsal articulation (to phallapodeme) practically at same level as ventral articulation (to hypandrium). Basiphallus and distiphallus (Fig. 17) together forming a compact structure with the upper surface apparently derived from the basiphallus, lower part (distiphallus) dominated by a pair of basal sclerites usually enveloping much of the distiphallus like the halves of a clamshell. Phallapodeme rod-like, often somewhat curved; anterior portion moderately dilated in some species. Ejaculatory apodeme small, shield-like and weakly sclerotized, seemingly absent in some species.

Female terminalia (Figs 66-76). Tergite 8 completely divided medially into two large, subtriangular, lateral sclerites. Tergite 10 oval with truncate to slightly emarginate anterior margin; surface convex, with weakly sclerotized median longitudinal strip and a pair of erect to slightly retrorse setulae near middle, densely microtrichose except anteriorly and laterally. Cerci dorsally concave and scoop-shaped, seamlessly fused with tergite 10 , dorsally shining with a larger and a shorter setula near middle and a few setulae near apex; each cercus ending in two short, flat, closely appressed bristles (anterior one broader than posterior one). Sternite 7 longer than preceding sternites. Invaginated intersegmental membrane behind sternite 7 with transverse strip of proclinate microtrichia (except in L. quadrisquamosa). Sternite 8 roughly $\pi$ - or U-shaped, weakly sclerotized except for the prominent, lip-like posterior margin which bears two pairs of small setulae. Sternite 10 roughly semicylindrical, dorsolaterally contiguous to lateral margins of tergite 10 , embracing base of cerci; ventral portion weakly sclerotized posteriorly and medially. Spermathecae (Figs $77-83$ ) usually 3 (in some species only 2); surface more or less striate; shape and size variable depending on species or species group, base usually with deep invagination beside (not surrounding) insertion of spermathecal duct (Fig. 78) (except L. rutricauda) and shallow distal invagination (except L. evanescens and L. rutricauda); paired spermathecae contiguous, on very short individual ducts (in two of the species with only 2 spermathecae each spermatheca is connected to the genital chamber by a separate long duct); spermathecal ducts sclerotized for very short distance beyond spermatheca. In three species (L. gibba, L. quadrisquamosa, L. rutricauda) elongate, paired accessory glands were discovered (Fig. 70); these extremely delicate structures are easily overlooked or damaged during preparation and probably occur in all species.

Immature stages. Larvae and puparia remain unknown. Eggs dissected from gravid females of L. rutricauda have long, thin micropylar processes. Eggs of L. angusticercus apparently lack micropylar processes; eggs of other species are unknown.

\section{Habitat preference and biology}

Virtually nothing is known about the biology of Lepidosina, and the larval habitat remains unknown. Some of the Lepidosina females we examined contained eggs with long micropylar processes, suggesting a wet or frequently inundated larval habitat. Most collections of this genus have been made by sweeping in floodplains, mangrove swamps, varzea, and other relatively low, wet areas. The majority of specimens are from low elevations, usually well under $1,000 \mathrm{~m}$ (rarely up to $1,500 \mathrm{~m}$, see L. argentinensis). Unlike many other Sphaeroceridae, Lepidosina species are usually not attracted to dung. This is well exemplified by a collection of L. rutricauda taken by the authors near Misahuallí (Napo, Ecuador). Even though this species was one of the most common Sphaeroceridae collected by aerial sweeping in the varzea near a river (almost 230 specimens collected), not a single specimen was found in dung traps operated at the same location (numerous other Sphaeroceridae genera were obtained from these traps). On the other hand, a small series of pan traps placed on a compost heap (containing kitchen refuse and plant clippings) uphill above the varzea yielded two males of $L$. rutricauda and one female of $L$. angusticercus (the latter was very rare in sweep samples). These results seem to indicate an at least moderate attraction to decaying vegetable matter. The notable exception in the genus is L. evanescens, which was mostly collected on dung, guano or carrion. The record of one male of $L$. eva- 
nescens on guano in a Venezuelan cave is especially noteworthy.

\section{Phylogeny of Lepidosina species}

Monophyly of the genus. The monophyly of Lepidosina is established by the following suite of synapomorphies (plesiomorphic conditions in parentheses): (1) Male sternites 6-8 completely fused and symmetrical or almost symmetrical, probably forming a complete ring in the Lepidosina ground plan even though in two species the ring is open ventrally (synsternite $6+7$ separate from sternite 8 ; strongly asymmetrical and not forming a ring); (2) hypandrium-epandrium connection strongly narrowed, weakened and translucent, somewhat flexible (hypandrium broadly, tightly and rigidly connected to ventral margin of epandrium); (3) hypandrium with greatly reduced anterior apodeme (hypandrial apodeme rod-like, well developed); (4) postgonites indistinct and weakly sclerotized, more or less translucent (postgonites sclerotized and pigmented); (5) postgonite-hypandrium connection approximately lateral to postgonite-phallapodeme connection; connection weak, inconspicuous and difficult to pinpoint (postgonite-hypandrium connection distinctly ventral to postgonite-phallapodeme connection; connection strong and well defined); (6) phallus of peculiar structure: mainly consisting of a large dorsal plate here interpreted as the basiphallus and a large ventral portion here interpreted as the distiphallus, both extending to base of phallus (phallus of different structure: basiphallus cylindrical to short and ring-like, basal to distiphallus, distiphallus not extending to base of phallus); (7) female tergite 10 seamlessly fused with scoop-shaped cerci (tergite 10 free from more or less cylindrical cerci); (8) female cercus with contiguous, staggered apical and preapical flattened bristles (apical bristles not flattened).

Comments on generic apomorphies. Character (1) appears to be unique within the family Sphaeroceridae. All other genera have strongly asymmetrical sternites 6-8 though in some groups these sternites may be fused into a single sclerite (e.g., many Leptocera Olivier, 1813). Characters of the hypandrial complex also seem to be unique but this character system has not been thoroughly studied in the family. To our knowledge the narrow, membranous hypandrium-epandrium connection typical of Lepidosina (character 2) does not occur elsewhere in the Sphaeroceridae. Reduced hypandrial apodemes (character 3) have been recorded from some Limosininae (e.g., most Opacifrons Duda, 1918; Marshall \& Langstaff, 1998), where they obviously evolved independently. A fusion of female tergite 10 and cerci (character 7) has evolved independently in Palaeocoprina Duda, 1920 (Marshall, 1998), Rudolfina Roháček, 1987, as well as some species of Opalimosina Roháček, 1983 (Roháček, 1983a, 1985), Leptocera (Roháček, 1982) and Rachispoda Lioy, 1864 (Roháček, 1991) but in these genera the apical bristles of the cercus are either not flattened or else they are inserted beside each other (Palaeocoprina). Flattened apical bristles (character 8) also occur in Opacifrons (two inserted beside each other; Marshall \& Langstaff, 1998) and in Archiceroptera Papp, 1977 (single bristle) but in these genera the cerci are not fused to tergite 10 (though the whole complex is strongly sclerotized and forms one functional unit similar to Lepidosina). Lepidosina lacks the asymmetrical epandrium that characterizes the very speciose Neotropical clade of Archiceroptera, Bromeloecia Spuler, 1924, Robustagramma Marshall \& Cui, 2005, and Pterogramma Spuler, 1924, further demonstrating that similarities between the female terminalia of some members of this clade and Lepidosina are homoplasious.

\section{Characters used in phylogenetic analysis}

Twenty-four morphological characters, mostly from male legs and male terminalia, were used to determine relationships within the genus (Table 1). Because the sister group of Lepidosina is unknown, characters were polarized based on a generalized Limosininae ancestor. The plesiomorphic state of each character is coded " 0 ", apomorphic states are coded "1" or " 2 ". All characters except 18 are unordered.

Leg and wing characters

1. Male fore femur, posteroventral bristles in distal half: 0 - long; 1 - very short.

2. Male fore tibia: 0 - simple; 1 - swollen, with anterodorsal concavity in distal half.

3. Male fore tarsus: 0 - simple; 1 - flattened.

4. Male mid tibia, middle anterodorsal bristle: 0 - present; 1 - absent.

5. Male mid tibia, middle of ventral surface: 0 - simple, evenly setulose; 1 - flattened, largely bare.

6. Male mid tibia, posteroventral row of hairs: 0 - hairs normally developed or very small; 1 - hairs becoming gradually stouter and longer towards apex of tibia.

7. Male mid tibia, apicoventral bristle: 0 - long (as in female); 1 - shortened (much shorter than in female).

8. Male mid tibia; fine, long, hair-like bristles closely appressed to apicoventral bristle: 0 - absent; 1 - one or two present.

9. Male hind tibia, middle of ventral surface: 0 - simple, evenly setulose; 1 - flattened, largely bare.

10. Male hind tibia, apicoventral hairs: 0 - short; 1 greatly enlarged.

11. Male hind tarsus, tarsomere 2: 0 - slightly enlarged; 1 - greatly swollen.

12. Wing, discal cell: 0 - closed; 1 - open through loss/desclerotization of $\mathrm{dm}-\mathrm{cu}$ and penultimate sector of M.

Male terminalia

13. Sternite 5, disc: 0 - with numerous setulae (Fig. 49); 1 - bare or almost bare (i.e. at most with two pairs of setulae) (Fig. 32).

14. Sternite 5, bristles at posterior margin: $0-$ small; $1-$ at least two pairs distinctly enlarged (Fig. 44).

15. Sternite 5; two pairs of translucent, scale-like bristles at posterior margin: 0 - absent; 1 - present (Fig. 32).

16. Synsternite 6-8: 0 - showing primary asymmetry, not forming complete ring; 1 - forming complete, symmetrical ring (but ventrally sometimes with secondarily asymmetrical processes in genital pouch); 2 - symmet- 
rical, open ventrally (Fig. 49). Note: The plesiomorphic state does not occur in Lepidosina.

17. Synsternite 6-8, anterodorsal apodeme: 0 - absent; 1 - strongly developed (Fig. 11).

18. Genital pouch, accessory sclerite: 0 - absent; 1 - present, simple (Fig. 21); 2 - present, with denticulate fields (Fig. 16). Character ordered.

19. Epandrium; pair of translucent, scale-like, ventral bristles: 0 - absent; 1 - present (Fig. 31).

20. Surstylus, 1-2 very long and strong bristles: $0-$ absent; 1 - present (Fig. 41).

21. Basiphallus, length: 0 - short (Fig. 30); 1 - long, extending to apex of distiphallus (Fig. 17).

22. Distiphallus, groups of strongly sclerotized spines: $0-$ absent; 1 - present (Fig. 47).

Female reproductive tract

23. Spermathecae: 0 - two closely paired plus one single (Fig. 77); 1 - two, on long, separate ducts (Fig. 80); 2 two, closely paired on very short ducts (Fig. 82).

24. Spermatheca, deep basal invagination beside insertion of spermathecal duct: 0 - absent (Fig. 80); 1 - present, hemispherical (Fig. 77); 2 - present, elongate with conical apex (Fig. 83).

Notes on some characters used in the analysis. Many of the characters mentioned here are sexually dimorphic leg characters. Within the Limosininae sexual dimorphism of legs is common, occurring most frequently in mid legs, but less so in fore and hind legs. Lepidosina is remarkable in that the majority of species show sexual dimorphism in all three pairs of legs. Sexual dimorphism of the hind tibiae as described here seems to be unique for Lepidosina, although certain species of the genus Bromeloecia exhibit very different sexually dimorphic hind tarsi (Marshall, 1983). Strikingly similar modifications of the male fore legs (swollen fore tibia with distal, anterodorsal emargination; flattened fore tarsi) are found in the clunipes-group of Spelobia Spuler, 1924 (Marshall, 1985; Roháček, 1983a, b). This convergent development within two distantly related genera is probably due to similar

TABLE 1. Character state matrix for species of Lepidosina.

\begin{tabular}{lrrr}
\hline & \multicolumn{3}{c}{ Character numbers } \\
\cline { 2 - 4 } Species & 1234567890 & 1234567890 & 1234 \\
\hline ancestor & 0000000000 & 0000000000 & 0000 \\
L. evanescens & 0000001000 & 0100010000 & 0022 \\
L. platessa & 1110000000 & 0100020000 & $00 ? ?$ \\
L. proxineura & 1111101111 & 1000010000 & $10 ? ?$ \\
L. rutricauda & 1110101110 & 1001011000 & 1110 \\
L. multispinulosa & 1110101110 & 1001021000 & $11 ? ?$ \\
L. cubensis & 1110101111 & 1001011000 & 1001 \\
L. argentinensis & 1110111110 & 1011011100 & 1001 \\
L. angusticercus & 1111111110 & 1011111201 & 1011 \\
L. quadrisquamosa & 1111111110 & 1011111201 & 1001 \\
L. inaequalis & 1111111110 & 1011111211 & 1001 \\
L. gibba & 1110111110 & 1011111211 & 1001 \\
\hline
\end{tabular}

behaviours (gripping and/or stroking of the female thorax or head during copulation?), which apparently lead to similar morphological adaptations. While the occurrence of series of stout ventral bristles on male mid femur and tibia has occurred many times convergently in the Limosininae, the shortening of the ventroapical bristle, and the occurrence of closely appressed, long, hair-like bristle in many Lepidosina males again seems to be unique within the family (in Opacifrons the ventroapical bristle is even more shortened than in Lepidosina but in this case there is no sexual dimorphism).

Flattened, scale-like bristles strikingly similar to those of L. gibba and related species also occur on the subanal plate of some species of Paralimosina Papp, 1973 (Roháček \& Papp, 1988), but this is certainly a convergent similarity.

Reduction of spermathecal numbers from three to two is uncommon in Limosininae outside the genus Bitheca Marshall, 1987 (as opposed to the four other subfamilies Sphaerocerinae, Copromyzinae, Homalomitrinae and Tucminae). Remarkably, reduction in Lepidosina has happened independently at least three times and in two different ways: either through loss of one of the paired spermathecae or through loss of the single, unpaired spermatheca. The latter appears to be unique within Limosininae.

\section{Results of analysis}

The analysis yielded four most parsimonious cladograms (tree length $=35$, consistency index $=0.80$, retention index $=0.86$, rescaled consistency index $=0.69$ ). This number is reduced to two (Fig. 10) when trees that contain branches with a length of zero under either ACCTRAN or DELTRAN optimization are eliminated.

The most plesiomorphic species of the genus is L. evanescens, which does not show the striking sexual dimorphism of the fore legs present in all other species of the genus. The second most basal species is L. platessa, which lacks most of the sexually dimorphic characters of the male mid leg linking the rest of the species in the genus in a group of nine more derived species. Within the latter group, L. proxineura occupies the most basal position because of the relatively primitive sternite 5 (lacking long bristles) and synsternite 6-8 (lacking anterior apodeme).

The remaining species fall into two distinct groups, the L. rutricauda-group (L. rutricauda, L. multispinulosa) and the L. gibba-group (L. cubensis, L. argentinensis, $L$. angusticercus, L. quadrisquamosa, L. inaequalis, $L$. gibba). The male genitalia of the L. rutricauda-group are very distinctive (distiphallus with groups of sclerotized teeth). The female of L. multispinulosa is unknown, but possible additional female synapomorphies (now known only from $L$. rutricauda) include anterior apodemes of sternite 10, two spermathecae on long separate ducts, and spermathecae with strongly bent long axes.

The sister group to the L. rutricauda-group, the $L$. gibba-group, is defined only by the deep hemispherical invagination of the spermatheca beside the insertion of the spermathecal duct. With the exclusion of the basal 


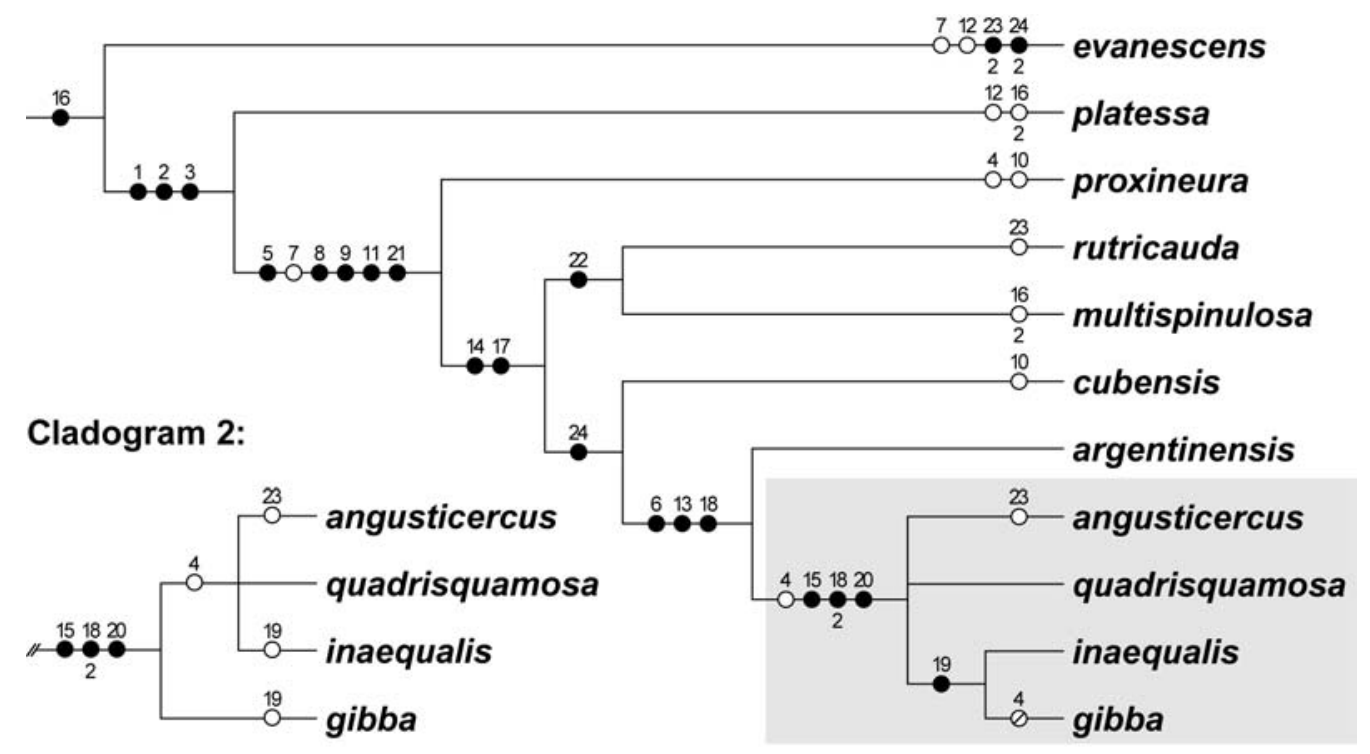

- unique synapomorphy
$\bigcirc$ convergence
$\oslash$ reversal

Fig. 10. Species level phylogeny of Lepidosina. Two of the four most parsimonious trees (DELTRAN optimization; trees containing branches with a length of 0 not shown). Both trees differ only with regard to the relationships within a group of four species including L. gibba (highlighted with grey in cladogram 1). For cladogram 2 only the portion that differs from cladogram 1 is shown. Character numbers are given above the circles, states for multistate characters (if different from " 1 " or " 0 ") below the circles .

species in the clade, L. cubensis, the L. gibba group is defined by a similarly shaped accessory sclerite in the genital pouch, a largely bare disc of sternite 5 , and a strongly developed row of posteroventral bristles on the male mid tibia. With the further exclusion of L. argentinensis the remaining species in the L. gibba group form a strongly supported clade characterized by three distinctive synapomorphies of the male terminalia (sternite 5 with scale-like bristles; genital pouch with denticulate accessory sclerite; surstylus with long, thick, curved bristles). The two cladograms for these four very similar species (L. angusticercus, L. quadrisquamosa, L. inaequalis, L. gibba) suggest two alternative evolutionary scenarios: a clade with $L$. gibba and $L$. inaequalis as sister species characterized by the presence of scale-like bristles on the epandrium, or a clade with all species excluding L. gibba characterized by the absence of the middle anterodorsal bristle of the male mid tibia.

\section{Key to males of Lepidosina}

(For females see separate key below.)

1 Wing with discal cell open (Fig. 6), crossvein dm-cu absent Mid tibia not curved and flattened, middle anterodorsal bristle well developed, at least $2 / 3$ as long as distal anterodorsal. Second tarsomere of hind leg not strongly swollen. . . ................................ 2

- Wing with discal cell closed (Fig. 5), crossvein dm-cu present. Mid tibia curved and ventrally flattened (Fig. 9); middle anterodorsal bristle variable, but usually small or absent. Second tarsomere of hind leg strongly swollen, much broader than other tarsomeres. . . . . . . . . . . . 3
2 Apicoventral bristle of mid tibia long, distinctly longer than tibial width. Dorsal bristles of mid tibia strong, mid anterodorsal nearly twice as long as tibial width. Fore tibia with distal anterodorsal excavation. Fore tarsomeres strikingly broad and flat (as in Fig. 7), basitarsus twice as broad as mid basitarsus (Bolivia)................ L. platessa sp. n. - Apicoventral bristle of mid tibia shortened, shorter than diameter of tibia. Dorsal bristles of mid tibia moderately strong, mid anterodorsal hardly longer than tibial width. Fore tibia simple, not excavated. Fore tarsomeres not strikingly flattened, basitarsus not broader than mid basitarsus (Central and South America)......... L. evanescens sp. n.

3 Crossveins dm-cu and r-m close together, length of dm-cu much more than distance between crossveins. Hind tibia with a few long ventral hairs near apex. Mid tibia lacking anterodorsal bristle at mid length (Brazil). . . . . . . . . . . ......................... proxineura sp. n.

- Crossveins dm-cu and r-m separated by at least length of dm-cu (Fig. 6). Hind tibia usually with short ventral hairs near apex (except in L. cubensis). Mid tibia with or without anterodorsal bristle at mid length. . . . . . . . . . 4

4 Sternite 5 and epandrium simple, lacking flat, scale-like

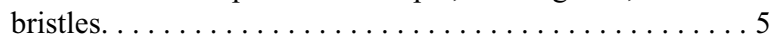

- Sternite 5 and sometimes also epandrium with flat, scalelike bristles (Figs $3,31,32$ ) . . . . . . . . . . . . . 8

5 Mid tibia with hairs of posteroventral row small but distinct, black and somewhat stout, spine-like (similar to Fig. 8) (Argentina)................. L. argentinensis sp. n.

- Mid tibia with hairs of posteroventral row very weak and fine, pale and hard to discern. . . . . . . . . . . . 6

6 Halter knob whitish, paler than stem. Hind tibia with a few long, thin, preapical ventral hairs. Distal posterodorsal bristle of mid tibia longer than distal anterodorsal (Cuba). . . . L. cubensis $\mathrm{sp} . \mathrm{n}$. 
- Halter knob brown, at least as dark as stem. Hind tibia with very short hairs near apex. Distal posterodorsal bristle of mid tibia either much smaller or almost as long as distal anterodorsal (South America). . . . . . . . . . . . . . . . 7

7 Mid femur with a shallow posteroventral depression in apical half, conspicuously delimited posteriorly by an arcuate, single row of hairs. Synsternite forming a complete ring, ventrally with sclerotized, digitate asymmetrical process. Distiphallus on each side with a single cluster of long spines (Fig. 65) (Colombia to Peru).... L. rutricauda sp. n.

- Mid femur simple, not depressed, posteroventral row of hairs hardly developed and not arcuate. Synsternite open ventrally, without sclerotized process. Distiphallus on each side with contiguous clusters of short and medium-sized spines (Fig. 47) (Ecuador, Peru).... L. multispinulosa sp. n.

8 Epandrium without scale-like bristles. Mid tibia without anterodorsal bristle at mid length. . . . . . . . . . . . . 9

- Epandrium with long, distally flattened, translucent (therefore sometimes difficult to see) scale-like bristles (Figs 3, 31). Mid tibia sometimes with anterodorsal bristle at mid length. ....................... 10

9 Large inner bristles of surstylus unequal, anterior bristle thin (Fig. 15). Cerci moderately tapered distally (Fig. 14). Subanal plate with only short bristles less than half as long as epandrial height. Postgonite drawn out into a pointed process posteriorly (Fig. 17) (Caribbean, Central and South America). . . . . . . . . . . . . . . . L. angusticercus sp. n.

- Both inner bristles of surstylus strong (Fig. 57). Cerci extremely tapered to an acute point (Fig. 58). Subanal plate with a pair of very long, pale, ventrally directed bristles; length subequal to epandrial height (Fig. 58). Postgonite without posterior process (Fig. 60) (Venezuela). . . . . . . . . ....................... quadrisquamosa sp. n.

10 Mid tibia lacking anterodorsal bristle at mid length (as in Fig. 9). Large, inner surstylar bristles unequal (Fig. 41), posterior one shorter and much thinner than anterior (southern U.S., Central America, Venezuela)......... L. inaequalis Mid tibia with anterodorsal bristle at mid length. Large, inner surstylar bristles of similar length and strength (Fig. 33) (Florida, Caribbean)................. L. gibba

\section{Key to known females of Lepidosina}

(Females of L. platessa, L. proxineura and L. multispinulosa are unknown.)

1 Wing with discal cell open, crossvein dm-cu absent (Fig. 6). Tergite 7 with a strong, conspicuous pair of bristles near middle, more removed from posterior margin than other strong bristles (Fig. 73). Each half of tergite 8 with a long, fine bristle (Fig. 73). Anterior margin of sternite 10 nearly straight (Fig. 74). Two closely paired spermathecae on single duct (Fig. 82); theca mushroom-shaped with very deep invagination above bottom; invagination with tapered, conical apex (Fig. 83) (Central and South America)....... .

L. evanescens sp. $\mathrm{n}$. Wing with discal cell closed, crossvein dm-cu present (Fig. 5). Tergite 7 without a strong, conspicuous pair of bristles near middle or (L. rutricauda) bristles present but not more removed from posterior margin than other bristles (Fig. 68). Tergite 8 with short setulae only. Anterior margin of sternite 10 either with distinct medial convexity or pointed projection (Figs 72, 76), or with strong ventrolateral apodemes (Fig. 70). Spermathecae usually $2+1$, if only two then each on long separate duct (Fig. 80); theca not mushroom-shaped, usually with hemispherical basal invagination and shallow apical concavity (Fig. 78)................. 2

2 Distal antero- and posterodorsal bristles of mid tibia subequal. Tergite 7 with conspicuous median pair of bristles which are at least as long as lateral ones (Fig. 68). Sternite 10 with a pair of strong ventrolateral apodemes from anterior margin (Fig. 70). Spermathecae $(1+1)$ with long axis bent by $45-90^{\circ}$ (Fig. 80); duct inserted on conical basal projection (Colombia to Peru). ......... L. rutricauda sp. n.

- Distal posterodorsal bristle of mid tibia clearly longer than distal anterodorsal. Tergite 7 with median pair of bristles inconspicuous, shorter than lateral ones (Fig. 71). Sternite 10 without anterior apodemes. Spermathecae $(2+1$ or $1+1)$ with long axis at most slightly bent; duct inserted at edge of hemispherical basal invagination (Fig. 77)........ 3

3 Base of spermathecae at least twice as wide as apex (Fig. 77). Anteroventral margin of sternite 10 evenly sclerotized, with small but pointed medial projection (Cuba)......... ............................ L. cubensis $\mathrm{sp.}$. Base of spermathecae at most $1.5 \times$ as wide as apex (Figs 78, $79,81)$. Anteroventral margin of sternite 10 either with a large pointed (often bicuspidate) or a smaller rounded medial projection, if pointed almost always divided by desclerotized or weakly sclerotized median strip (Fig. 76)...

4 Anteroventral margin of sternite 10 with rounded median projection, lacking medial desclerotized or noticeably weaker sclerotized strip (Fig. 72). Medial pair of setulae of sternite 8 separated by at least $4 \times$ the distance between setulae on each side. Spermathecae $1+1$ or $2+1 \ldots \ldots \ldots 5$ - Anteroventral margin of sternite 10 more acutely produced forward (Fig. 76), usually finely bicuspidate, divided by desclerotized or weakly sclerotized medial strip (sometimes indistinct in L. inaequalis). Medial pair of setulae of sternite 8 separated by less than $4 \times$ the distance between setulae on each side. Spermathecae $2+1 \ldots \ldots \ldots \ldots \ldots \ldots \ldots$

5 Spermathecae $1+1$, on long separate ducts, large, length 75-89 $\mu \mathrm{m}$. Microtrichose areas of cerci and tergite 10 broadly connected (Caribbean, Central and South America). Spermathecae $2+1$ (Fig. 78), paired spermathecae with very short individual ducts; size small, length of larger, single spermatheca $53 \mu \mathrm{m}$. Microtrichose areas of cerci and tergite 10 separated by bare area (Argentina). . . . . . . . . . . . . . L. argentinensis sp. $\mathrm{n}$.

6 Intersegmental membrane behind sternite 7 bare, lacking microtrichia. Sternite 8 small, only about $0.55 \times$ as wide as sternite 10 (Venezuela)........ L. quadrisquamosa sp. n. - Intersegmental membrane behind sternite 7 with transverse microtrichose area separated by bare area from sternite. Sternite 8 usually wider (about $0.8 \times$ as wide as sternite 10 ). . .......................... 7

$7^{*}$ Sternite 8 about $0.8 \times$ as wide as sternite 10 . Hind margin of sternite 10 microtrichose throughout (Florida, Caribbean). .

................................ gibba

- Sternite 8 only about $0.5 \times$ as wide as sternite 10 . Hind margin of sternite 10 microtrichose but with a bare gap between medial pair of setulae (southern U.S., Central America, Venezuela)................. L. inaequalis

Descriptions follow in alphabetical order.

* This couplet is tentative. 


\section{Lepidosina angusticercus Marshall \& Buck, sp. n.}

(Figs 7-9, 11-17)

\section{Description}

Head. Upper frons dark brown, with conspicuous pollinose areas; lower frons, antenna, gena and face pale brown (most females) to yellow (males); interfrontal bristles in three pairs, middle pair largest and two lowest pairs cruciate.

Thorax. Acrostichal bristles in ca. 8 rows at level of transverse suture, middle acrostichals enlarged, those between anterior dorsocentrals as large as prescutellar acrostichals. Posterior katepisternal bristle about as long as fore basitarsus, anterior katepisternal very small.

Legs. Fore femur of both sexes with two posterodorsal bristles; posteroventral bristles of distal half moderately long in female, extremely short in male. Fore tibia of male broad (Fig. 7), lower surface somewhat flattened and virtually bare, apical half strongly depressed anterodorsally. Fore tarsomeres of male strongly flattened (Fig. 7); first two tarsomeres similar, about twice as long as wide; third tarsomere about as wide as long; distal two tarsomeres almost twice as wide as long. Female fore tibia slender, neither flattened nor bare ventrally, without distal emargination; fore tarsus slender, not flattened. Mid femur of male ventrobasally with several short, black bristles in a V-shaped formation; anteroventral bristles longer than posteroventral ones. Mid tibia of male slightly curved (Fig. 9), flattened and bare ventrally; row of posteroventral bristles in distal half (Fig. 8) with bristles increasing in size distally and ending in a shorter, stout apical plus two closely appressed, long, thin, hair-like bristles; one small anterodistal bristle. Dorsal surface of male mid tibia with large, paired distal anterodorsal and posterodorsal bristles (latter inserted slightly lower than former), and large basal anterodorsal and a small corresponding posterodorsal bristle (latter inserted lower than former; Fig. 9). Female mid femur and mid tibia unmodified; mid femur with inconspicuous hairs near base; mid tibia dorsally with a strong anterodorsal at middle in addition to the proximal and distal pairs, ventrally with a large, stout, apical bristle (lacking thin, hair-like bristles), and a well-developed midventral bristle. Male hind tibia ventrally flattened and virtually bare, especially in distal half. Second tarsomere of hind leg swollen and twice as long as basitarsus. Female hind tibia simple, neither flattened nor bare ventrally. Second tarsomere of female hind leg somewhat stouter than distal tarsomeres but not swollen as in male.

Wing. Costa light brown, other veins relatively pale brown, more so posteriorly. Distance between crossveins $\mathrm{dm}-\mathrm{cu}$ and $\mathrm{r}-\mathrm{m} 1.5 \times$ length of dm-cu. Third costal sector $0.7 \times$ second. Halter, including stem, pale.

Male terminalia (Figs 11-17). Sternite 5 (Fig. 12) with bare disc; posterior margin with 6 medial bristles, middle two small, outer two on each side prominent and scalelike. Synsternite 6-8 (Fig. 11) forming a symmetrical ring, with broad anterodorsal apodeme projecting under tergites 3-5. Genital pouch with a U-shaped sclerite (Fig. $16)$, each half with a broad lateral plate and a compact multi-toothed inner plate. Epandrium (Fig. 14) short dorsally; subanal plate convex, somewhat shorter than perianal area, on a plane well posterior to that of cerci; cerci basally fused and distally contiguous, moderately tapered apically; apex narrowly truncate. Surstylus bilobed (Fig. 15), inner lobe broad and convex, outer lobe narrow, prominently projecting laterally, anterolaterally curved and ending in two closely spaced, large curved bristles, posterior bristle much larger than anterior. Phallus short and compact (Fig. 17), with basiphallus covering most of dorsal surface of distiphallus. Postgonite (Fig. 17) broad basally, concealing base of phallus in lateral view, gradually tapered distally.

Female terminalia. Tergite 7 with moderately long posterior bristles; middle pair slightly longer than tergite, shorter than lateral bristles. Each half of tergite 8 with short setulae only. Microtrichose patches of tergite 10 and of dorsal surface of cerci broadly connected, not separated by bare area. Transverse strip of microtrichia behind sternite 7 separated by bare area from that sternite. Sternite 8 ca. $0.85 \times$ width of sternite 10 ; distance between setulae of middle pair 4-6× distance of setulae on each side. Anterior margin of sternite 10 broadly emarginate ventrally, medially with a gently rounded convexity, not divided by desclerotized median strip; posterior margin of sternite densely microtrichose and with a pair of setulae. Spermathecae $(1+1)$ on separate ducts, elongate, large (length 75-89 $\mu \mathrm{m}$ ), shape more or less cylindrical with narrowed but parallel-sided distal part and a shallow apical invagination; densely ringed with transverse striae; duct inserted eccentrically beside hemispherical basal invagination of spermatheca, sclerotized portion of duct very short (length ca. $3 \times$ width of duct).

Eggs. One of the four dissected paratype females contained about a dozen large, elongate eggs, three times as long as wide and about $0.3 \times$ as long as abdomen, with a preapical depressed area; no visible micropylar process.

Type material. Holotype $\hat{\delta}$ and $1 \hat{\delta}$ paratype. Grenada. Concord Falls, Nutmeg Plantation, 4.i.1995, S.A. Marshall (DEBU). Other paratypes: $25 \delta, 29$ \% . Grenada. Grand Etang Rain Forest, 3.i.1995, S.A. Marshall (1 $q$, DEBU); Grand Etang, 4.i.1995, sweep wet trail, S.A. Marshall (3 9 , DEBU); Mt. Qua Qua, 2000', 3.i.1995, S.A. Marshall (2 $q$, DEBU). Dominica. Clarke Hall, 8.-10.i.1955, Malaise trap, W.W. Wirth, Bredin-Archbold Smithsonian Survey of Dominica $(5 \hat{\delta}, 4 q$, USNM). Puerto Rico. El Yunque Recreation area, Los Pirachos lookout, 1000 m, 5.ii.1989, grass, S.A. Marshall $(1 \hat{\delta}, 2$,, DEBU; $\hat{o}$ is "Barcode of Life" specimen DEBU0070). British Virgin Islands. Mt. Sage, 400 m, 13.vii.1979, N.L.M. Krauss (5 $ત$, 7 웅 USNM). Dominican Republic. Hato Mayor, Parque los Haitises, E of Trepada Alta, $12 \mathrm{~km} \mathrm{~W} \mathrm{El} \mathrm{Valle,} 18^{\circ} 59^{\prime} \mathrm{N}, 69^{\circ} 30^{\prime} \mathrm{W}, 145 \mathrm{~m}$, 6.vii.1992, mesic forest on limestone, J. Rawlins, S. Thompson, C. Young \& R. Davidson (1 $\left.\sigma^{\circ}, \mathrm{CMNH}\right)$. Panama. Canal Zone, Pedro Miguel, 10.iv.1923, R.C. Shannon (1 $\sigma^{\star}$, USNM). Ecuador. Napo, Jatun Sacha Reserve, $6 \mathrm{~km}$ E Misahuallí, 450 $\mathrm{m}, 2 . v .2002$, varzea sweep, M. Buck (30, DEBU, one is "Barcode of Life" specimen DEBU0071); same data but 5.v.2002, S.A. Marshall (1 $\widehat{0}$, DEBU); same data but 1.-2.v.2002, compost, yellow pans, M. Buck (1 $q$, DEBU); Pichincha, Sto. Domingo, 19.vi.1965, 600 m, L. Peña (2 ô, 5 @ , CNCI); Guayas, Cone [= Yaguachi Viejo], vi.1955, Levi-Castillo (20, USNM). 

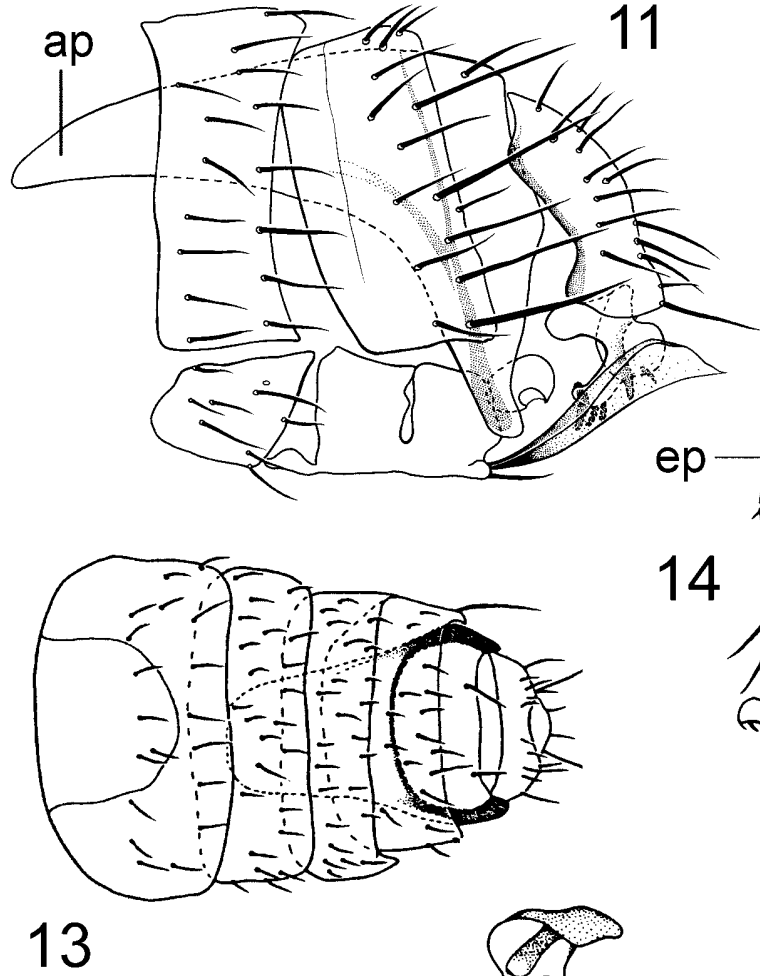

14

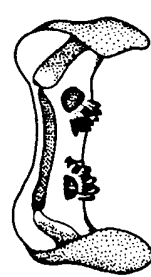

16
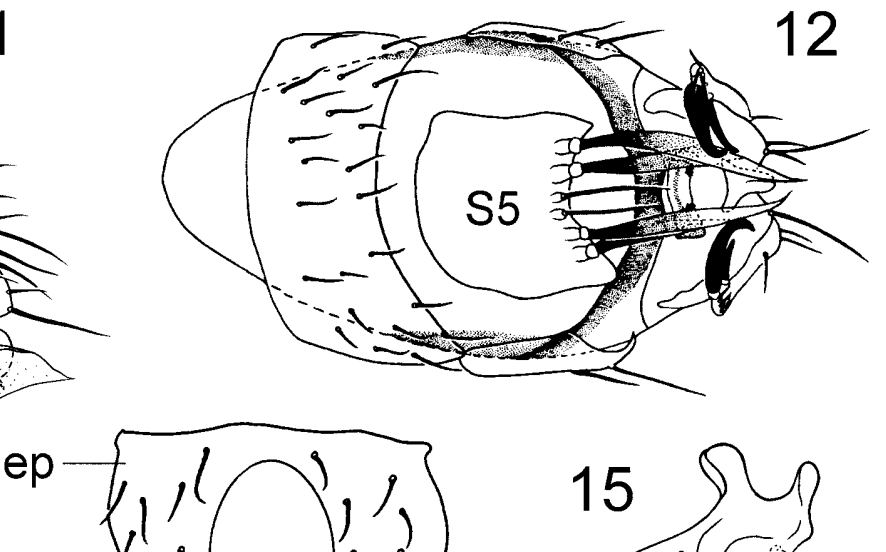

15

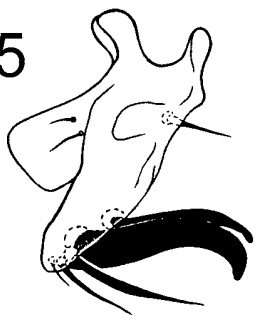

SS

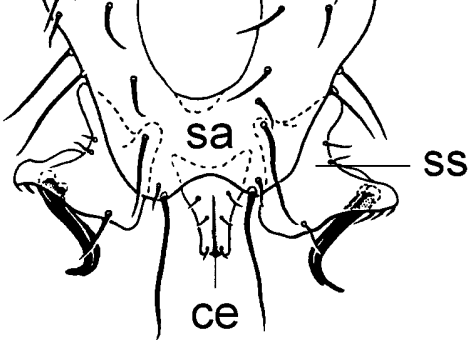

bph

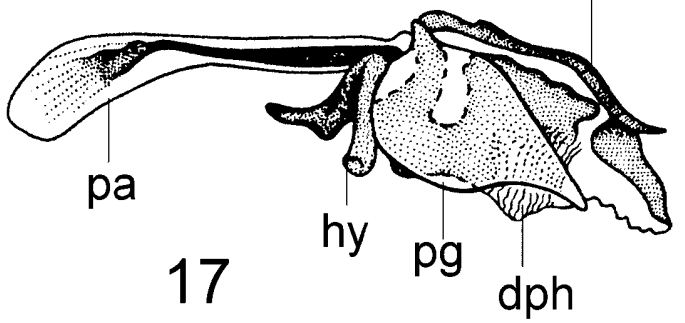

Figs 11-17. Lepidosina angusticercus sp. n., male: 11 - abdomen, segments 4-5 and terminalia, lateral; 12 - ditto, ventral; 13 abdomen, dorsal; 14 - terminalia, posterior; 15 - left surstylus, lateral; 16 - accessory sclerite of genital pouch; 17 - phallus and associated structures, lateral. ap - apodeme of synsternite $6-8, \mathrm{bph}-$ basiphallus, ce - cerci, dph - distiphallus, ep - epandrium, hy hypandrium, pa - phallapodeme, pg - postgonite, S5 - sternite 5, sa - subanal plate, ss - surstylus.

Peru. Ucayali, Pucallpa, 2.x.1954, E.L. Schlinger \& E.S. Ross

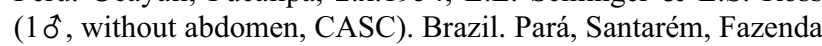
Taperinha, xi.1970, Exp. Perm. Amaz. (30, 4 ㅇ, MZSP); Bahia, Itabuna, Rerserva Ecologica CEPEC, 25.iii.1995, forest light trap, P.S. Terra (1 $\delta^{\star}$, MZSP).

Etymology. The specific epithet refers to the narrow male cerci.

Distribution. Caribbean (Grenada, Dominica, Dominican Republic, Puerto Rico, British Virgin Islands), Panama, Brazil, Ecuador (both sides of the Andes) and Peru.

Discussion. Lepidosina angusticercus is very similar to L. quadrisquamosa in possessing scale-like bristles only on sternite 5 (not on the epandrium), differing most obviously in details of the male cerci, surstyli and genital pouch sclerite. The presence of only two spermathecae is remarkable given the plesiomorphic retention of three spermathecae in the similar L. quadrisquamosa (several females were dissected to confirm this).

\section{Lepidosina argentinensis Marshall \& Buck, sp. n.}

(Figs 18-22, 71, 72, 78)

\section{Description}

Head. Upper frons dark brown, with conspicuous pollinose areas; lower frons, antenna, gena and face pale brown; interfrontal bristles in three pairs, middle pair largest, two lowest pairs with apices of bristles nearly meeting.

Thorax. Acrostichal bristles in ca. 8 rows at level of transverse suture, middle acrostichals enlarged, those between anterior dorsocentrals as large as prescutellar acrostichals. Posterior katepisternal bristle about as long as fore basitarsus, anterior katepisternal very small.

Legs. Fore femur of both sexes with two posterodorsal bristles; posteroventral bristles of distal half slightly long in female, extremely short in male. Fore tibia of male with apical third depressed anterodorsally; fore tibia setulose and not flattened ventrally. Fore tarsomeres of male broad with dense ventral setulae; first tarsomere longer than second, distal three tarsomeres subequal in length and width. Female fore tibia slender and without distal emargination; fore tarsus slender and not flattened. Male mid femur near base with short, somewhat stout, black bristles in a $\mathrm{V}$-shaped formation, posteroventral bristles at least as long as anteroventral ones. Mid tibia of male curved, dorsally with proximal, middle and distal anterodorsal bristles, and proximal and distal posterodorsal bristles; distal posterodorsal bristle slightly longer than distal 

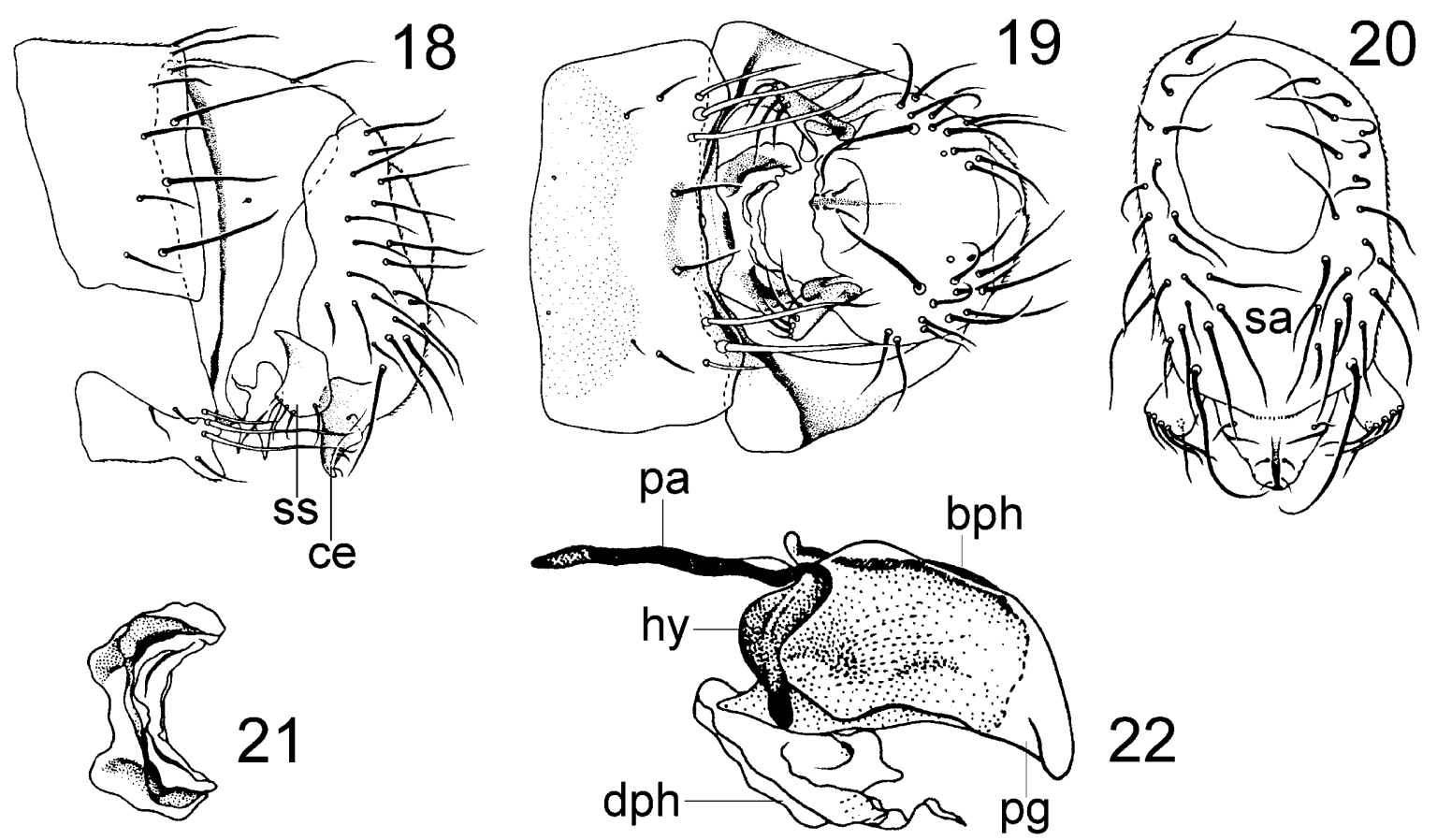

Figs 18-22. Lepidosina argentinensis sp. n., male: 18 - abdominal segment 5 and terminalia, lateral; 19 - ditto, ventral; 20 - terminalia, posterior; 21 - accessory sclerite of genital pouch; 22 - phallus and associated structures, lateral. bph - basiphallus, ce cerci, dph - distiphallus, hy - hypandrium, pa - phallapodeme, pg - postgonite, sa - subanal plate, ss - surstylus.

anterodorsal. Ventral surface of male tibia flattened, with a double row (anteroventral and posteroventral) of ventral bristles on distal 9/10, rows convergent near apex, space between them broad and bare; tibia ventroapically with one stout shorter bristle and two closely appressed long, thin hair-like bristles. Female mid femur and mid tibia unmodified; mid femur with inconspicuous hairs near base; mid tibia ventrally with a large, stout, apical bristle (lacking thin, hair-like bristles), and a well-developed midventral bristle. Male hind tibia not noticeably flattened ventrally, but rows of hairs farther apart than in female, leaving bare median strip. Second tarsomere of male hind tarsus swollen.

Wing. Costa pale brown, other veins whitish. Third costal sector $0.8 \times$ second. Crossveins dm-cu and $\mathrm{r}-\mathrm{m}$ separated by $1.5 \times$ length of $\mathrm{dm}-\mathrm{cu}$. Halter, including stem, pale.

Male terminalia (Figs 18-22). Sternite 5 simple (Fig. 19), with largely bare disc; posterior margin with 8 long but thin bristles including two pairs of large pale bristles probably homologous with the scale like bristles of some congeners. Synsternite 6-8 (Fig. 18) in a symmetrical ring, dorsal part broad, with relatively short anterodorsal apodeme (not projecting beyond tergite 5). Genital pouch with a transverse, posteriorly emarginate accessory sclerite (Fig. 21); sclerite lacking toothed plates. Epandrium (Fig. 20) short dorsally; subanal plate very large, almost as long as remainder of epandrium. Cerci basally fused and distally contiguous, forming a prominent, broad, bluntly rounded lobe. Surstylus small, simple, with a row of four long, thin, medially directed, distal bristles. Phallus short and compact (Fig. 22), with basiphallus covering most of dorsal surface of distiphallus. Postgonite
(Fig. 22) larger than phallus, concealing phallus in lateral view and extending beyond distiphallus apex.

Female terminalia very similar to L. angusticercus, differing as follows (Figs 71, 72, 78): Cerci with microtrichose area laterally and apically, separated by bare area from microtrichose patch on tergite 10 . Median pair of setulae of sternite 8 separated by about $7.5 \times$ the distance between setulae on each side. Spermatheca $(2+1)$ (Fig. 78) smaller and less elongate than in L. angusticercus; length of single spermatheca $53 \mu \mathrm{m}$; paired spermathecae slightly smaller than single one, and with extremely short individual ducts.

Type material. Holotype $\hat{\delta}$. Argentina. Salta, La Caldera, Camino la Cornisa, 1500 m, 27.ii.1992, roadside forest sweeps, S.A. Marshall (DEBU). Paratype ${ }^{\star}$. Argentina. Jujuy, Calilegua National Park, Aguas Negras, 500 m, 18.-28.xii.1987, gallery forest, Malaise FIT, S. \& J. Peck (DEBU).

Other material examined. Argentina. Salta, El Rey National Park, Río la Sala, 900 m, 5.-10.xii.1987, open stream side in forest, FIT, S. \& J. Peck (1 9 , DEBU).

Etymology. The specific epithet refers to the type locality.

Distribution. Only known from northern Argentina at altitudes from $500-1500 \mathrm{~m}$.

Discussion. This is the only species in the genus with a well developed row of posteroventral bristles on the male mid tibia but without flattened bristles on male sternum 5 . Unique diagnostic characters of the male terminalia include the presence of an accessory sclerite that lacks denticulate plates, and the relatively short anterodorsal apodeme of synsternite 6-8 (not extended beyond tergite $5)$. 


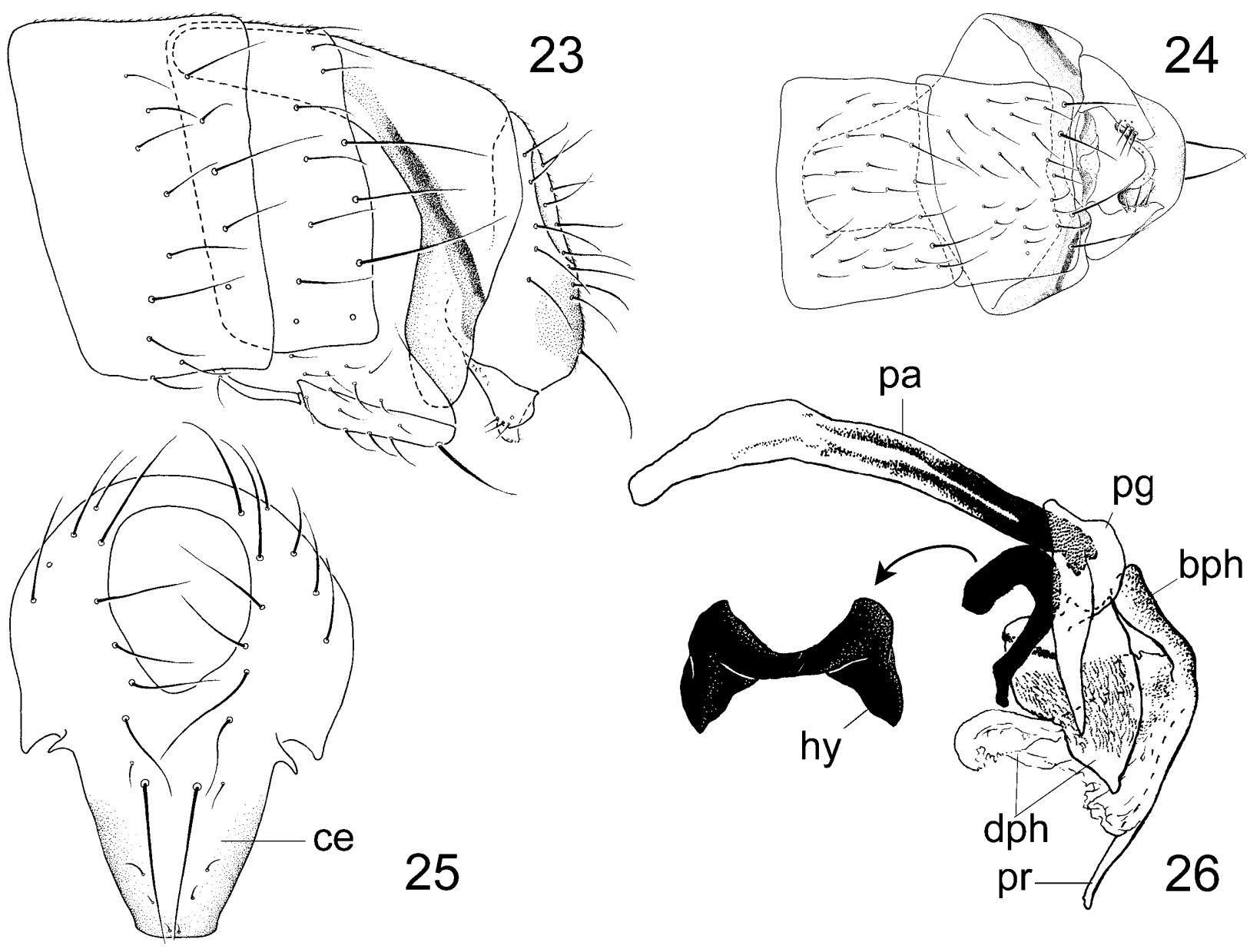

Figs 23-26. Lepidosina cubensis sp. n., male: 23 - abdominal segments 4-5 and terminalia, lateral; 24 - ditto, ventral; 25 - terminalia, posterior; 26 - phallus and associated structures, lateral (arrow: hypandrium, anterior). bph - basiphallus, ce - cerci, dph - distiphallus, hy - hypandrium, $\mathrm{pa}$ - phallapodeme, $\mathrm{pg}$ - postgonite, $\mathrm{pr}$ - apical process of distiphallus.

\section{Lepidosina cubensis Marshall \& Buck, sp. n.}

(Figs 23-26, 66, 67, 77)

\section{Description}

Head brown; frons with conspicuous pollinose areas; lower frons, antenna, gena and face pale brown; interfrontal bristles in four pairs, lowest pair weak.

Thorax. Acrostichal bristles in 6-8 rows at level of transverse suture, middle acrostichals enlarged, as long as prescutellar dorsocentrals. Posterior katepisternal bristle about as long as fore basitarsus, anterior katepisternal very small.

Legs. Fore femur of both sexes with two posterodorsal bristles near middle; posteroventral bristles of distal half moderately long in female, extremely short and hair-like in male. Fore tibia of male with apical half depressed anterodorsally; ventral surface of male fore tibia flattened and virtually bare. Fore tarsomeres of male broad with dense ventral setulae; first tarsomere longer than second, distal three tarsomeres subequal in length and width. Male mid femur ventrobasally with a $\mathrm{V}$-shaped formation of inconspicuous, hardly darkened, erect, hair-like bristles. Mid tibia of male dorsally with proximal, middle and distal anterodorsal bristles and proximal and distal posterodorsal bristles; distal posterodorsal bristle longer than distal anterodorsal; ventral surface of male tibia strongly flattened ventrally, hairs of antero- and posteroventral rows hardly differentiated, only noticeable in apical fourth of tibia where rows converge towards apical bristle; tibia ventroapically with a stout shorter bristle and a closely appressed long, thin, hair-like bristle. Female mid femur and mid tibia unmodified; mid femur without $\mathrm{V}$-shaped formation of erect hairs near base; mid tibia ventrally with a large, stout, apical bristle (lacking thin, hair-like bristle), and a well-developed midventral bristle. Male hind tibia flattened ventrally, especially in mid section, and largely bare except apically where hairs increase in length; apical two hairs nearly as long as basitarsus. Second tarsomere of male hind leg swollen and twice as long as basitarsus. Female hind tibia simple, neither flattened nor bare ventrally, distally without enlarged hairs. Second tarsomere of female hind leg somewhat stouter than distal tarsomeres but not swollen as in male.

Wing veins brown. Crossveins dm-cu and r-m separated by twice length of dm-cu. Third costal sector $0.8 \times$ second. Halter, including stem, pale.

Male terminalia (Figs 23-26). Sternite 5 simple (Fig. 24), with setulose disc; posterior margin bearing two pairs of long, thin bristles (possibly homologous with the scale 
like bristles of some congeners). Synsternite 6-8 (Fig. 23) in a symmetrical ring, ventral portion narrow and weakly sclerotized; anterodorsal apodeme large, projecting under tergite 5 and posterior margin of tergite 4 . Genital pouch with a small, medially desclerotized, asymmetrical accessory sclerite, densely microtrichose on each side. Epandrium short dorsally (Fig. 25); subanal plate large, fused with cerci to form a prominent, broad, subquadrate lobe. Surstyli small (Fig. 23), simple, with a marginal row of small bristles distally. Hypandrium very dark (Fig. 26), middle part with dorsal emargination to accommodate phallapodeme. Phallus short and compact (Fig. 26), with basiphallus extending along entire length of dorsal surface of distiphallus and projecting beyond apex of distiphallus as a narrow process. Postgonite pale (Fig. 26), abruptly narrowed into slender distal portion, inconspicuously squeezed between the compact, dark hypandrium and the large, triangular, weakly striate, basolateral lobe of the distiphallus.

Female terminalia similar to L. angusticercus, differing as follows (Figs 66, 67, 77): Microtrichose patch of tergite 10 relatively small, broadly separated from very sparse microtrichose patch in apical half of dorsal surface of cerci. Sternite $80.8-1.0 \times$ as wide as sternite 10 , with medial pair of setulae of $2.5-3.5 \times$ as far apart as setulae on each side. Anterior margin of sternite 10 with short, triangular medial projection, evenly sclerotized, lacking medial weakly sclerotized strip. Spermathecae $(2+1)$ large (length of slightly larger single spermatheca ca. 80-85 $\mu \mathrm{m}$; Fig. 77), very dilated basally, width at base at least twice width at apex; surface striation finer than in $L$. angusticercus; individual ducts of paired spermathecae extremely short.

Type material. Holotype $\delta$ (DEBU) and 25 paratypes ( 60 , 19ㅇ, DEBU, COEB; 20 are "Barcode of Life" specimens DEBU0062 and 63). Cuba. Santiago, Gran Piedra, segundo chorroito, $600 \mathrm{~m}, 7 .-17 . x i i .1995$, km 8, forest stream FIT, S. Peck, 95-83.

Etymology. The specific epithet refers to the type locality. Distribution. At present only known from Cuba.

Discussion. Lepidosina cubensis is one of only two species with enlarged ventroapical hairs on the male hind tibia. The other species, L. proxineura, is easily separated from L. cubensis based on the closely approximated crossveins (separated by less than length of dm-cu). This species is also recognizable by the absence of distinct posteroventral bristles on the male mid tibia in conjunction with pale halters (this character combination only shared with L. proxineura). The long, slender, apical process of the basiphallus (projecting far beyond the distiphallus) is unique for the species.

\section{Lepidosina evanescens Marshall \& Buck, sp. n.}

(Figs 6, 27-30, 73, 74, 82, 83)

\section{Description}

Head pale brown, darker dorsally, frons with inconspicuous pollinose areas; interfrontal bristles in three equal pairs plus two small lower setulae. Upturned genal bristle relatively short, a little longer than half as long as vibrissa.

Thorax. Acrostichal bristles in ca. 8 rows at level of transverse suture, middle acrostichals only slightly enlarged. Prescutellar acrostichal bristles twice as long as other acrostichals, prescutellar dorsocentral bristles twice as long as other dorsocentrals, as long as scutellum. Posterior katepisternal bristle about $3 / 4$ as long as fore basitarsus, anterior katepisternal absent or minute.

Legs. Fore legs not sexually dimorphic. Fore femur with 3-4 posteroventral bristles in apical half and 2-4 dorsal to posterodorsal bristles. Fore tibia slender, neither depressed anterodorsally in distal half nor flattened ventrally. Fore tarsus not flattened, with dense ventral setulae; first tarsomere about twice as long as second; other tarsomeres subequal in length and width. Mid legs with only slight sexual dimorphism. Mid femur with bristles of antero- and posteroventral rows more crowded and more erect towards base in male than in female; those of anteroventral row also becoming darker and stouter in male. Mid tibia not flattened ventrally, with two nearly contiguous ventral rows of bristles; bristles slightly stouter in male than in female; ventroapical bristle much shorter in male than in female; no long, thin hair-like bristle(s) next to ventroapical. Dorsal surface of mid tibia with three anterodorsal and two posterodorsal bristles as usual for the genus; distal posterodorsal bristle longer than distal anterodorsal; bristles of equal length in both sexes. Hind leg without apparent sexual dimorphism; tibia evenly setulose and not flattened ventrally, ventroapically without long hairs; second tarsomere stouter than distal three tarsomeres but not distinctly swollen.

Wing (Fig. 6) with crossvein dm-cu absent, vein M present merely as a fold beyond $\mathrm{r}-\mathrm{m}, \mathrm{CuA}_{1}$ very weak beyond bend near mid-length of distally open discal cell. Veins pale brown. Third costal sector $0.6 \times$ second costal sector. Halter pale brown, with whitish stem.

Male terminalia (Figs 27-30). Sternite 5 short (Fig. 28), weakly concave posteriorly. Synsternite 6-8 (Fig. 27) in a symmetrical ring, dorsal part broad and without hairs or bristles, not bearing a distinct anterior apodeme. Intersegmental membrane on left side between synsternite 6-8 and epandrium with a small, oval, dark accessory sclerite. Genital pouch with a weakly sclerotized, small, simple sclerite and a ring-shaped sclerite (modified, nonfunctional right spiracle 7?). Epandrium (Fig. 29) short dorsally, with relatively numerous hairs and without outstanding bristles; subanal plate high, ventrally terminating in elongate, well separated cerci. Surstylus (Figs 27, 29) oriented parallel to cerci, elongate and more or less parallel-sided, with rounded apex. Hypandrium (Fig. 30) a relatively weak, transverse rod, sharply bent posteriorly at sides to meet bases of surstyli. Postgonite elongate (Fig. 30), with slender apical portion. Basiphallus covering basal half of dorsal surface of distiphallus (Fig. 30); distiphallus divided medially into paired plates enveloping much of the phallus laterally and ventrally; membranous, eversible apical portion with fine transverse 


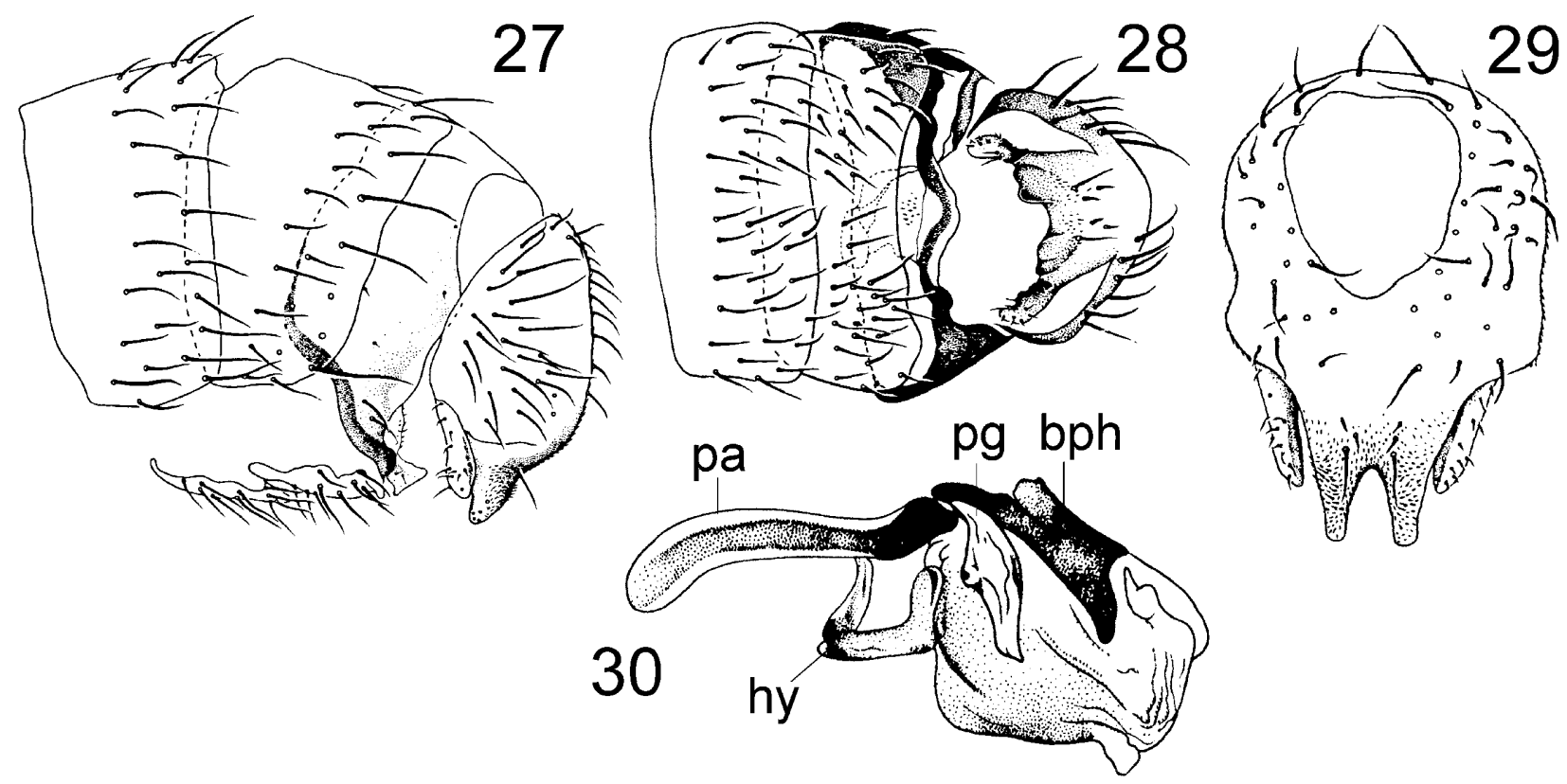

Figs 27-30. Lepidosina evanescens sp. n., male: 27 - abdominal segments 4-5 and terminalia, lateral; 28 - ditto, ventral; 29 - terminalia, posterior; 30 - phallus and associated structures, lateral. bph - basiphallus, hy - hypandrium, pa - phallapodeme, pg - postgonite.

striae. Ejaculatory apodeme simple, shield-like, weakly sclerotized, with four small sensory pores.

Female terminalia (Figs 73, 74, 82, 83). Tergite 7 (Fig. 73) with a posterior row of long bristles, the middle two of which are longer than the tergite, inserted more anteriorly and thicker than the other bristles; bristles of preceding tergites small except lateral bristles of tergite 6 . Each half of tergite 8 with a long but thin anteromedial bristle (Fig. 73). Cercus truncate apically, with anterior of two flattened bristles very broad, $3 \times$ as broad as posterior one; dorsal surface of cerci sparsely microtrichose, microtrichose areas of tergite 10 and cerci narrowly connected. Transverse strip of microtrichia behind sternite 7 contiguous with that sternite, not separated by bare area as in other species. Sternite 8 (Fig. 74) about $0.7 \times$ as wide as sternite 10 , with very deep but narrow anterior emargination; setulae at hind margin nearly equidistant. Anterior margin of sternite 10 almost straight (Fig. 74), not emarginate ventrally; posterior margin densely microtrichose. Spermathecae (2) large (length 80-84 $\mu \mathrm{m}$; Figs 82, 83), very closely paired, subsessile; shape mushroom-like; base with a very deep invagination from the side that is conically tapered apically (Fig. 83), invagination reaching level of distal constriction; mushroom-like cap evenly convex, without central invagination as in most other species; surface of lower portion with a few very deeply incised grooves. Spermathecal duct unsclerotized throughout, individual ducts inserted at edge of basal invagination.

Type material. Holotype $\hat{\delta}$ and $1 \hat{\delta}$ paratype. Ecuador. Esmeraldas, $11 \mathrm{~km}$ SE San Lorenzo, La Chiquita, $5 \mathrm{~m}$, 9.-10.vi.1975, carrion, S. Peck (DEBU). Other paratypes: $12 \hat{0}$, 6 ㅇ. Ecuador. Same locality as holotype, 10.-11.vi.1975, dung trap, S. Peck (3 $\delta, 2$ ㅇ, DEBU); La Chiquita, 7.-8.vi.1975, dung, S. Peck $(2 \hat{\delta}, 1+$, DEBU). Bolivia. Santa Cruz, Perseverancia,
Salitral, 24.-28.ix.1996, Rossi \& Bettella (1ð, DEBU); Ixiamas, xii.1921-22, Mulford Bio. Expl., W.M. Mann (1오, AMNH). Costa Rica. Heredia, $10 \mathrm{~km}$ W Puerto Viejo, Selva Verde, 2.-6.iii.1991, yellow pan trap, B.J. Sinclair (1 ô, INBC); Limón, Estrella Valley, Pandora, 20.ii.1984, carrion trap, H. Howden (1 9 , DEBU). Colombia. Leticia, 28.ii.1974, V. Nealis (1 9 , DEBU). Peru. Madre de Dios, Manú National Park, Cocha Cashu Biological Station, 380 m, 23.-30.viii.1986, Malaise trap, D.C. Darling, ROM863569 (3 0 , ROME). Venezuela. Miranda, $20 \mathrm{~km} \mathrm{~W}$ Curiepe, Cueva Alfredo Jahn, 200 m, 7.iii.1971,

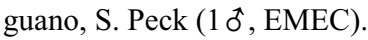

Etymology. The specific epithet refers to the evanescent crossvein dm-cu.

Distribution. Costa Rica, Venezuela; elsewhere in South America both west of the Andes (Ecuador) and east of the Andes (Colombia, Peru, Bolivia).

Discussion. Lepidosina evanescens lacks many of the distinctive characters that link most other Lepidosina, such as the strongly modified male fore tibia and tarsi, ventrally flattened male mid and hind tibiae, strongly swollen second male hind tarsomere and anterodorsal apodeme of syntergosternite 6-8. The distally open discal cell of the wing is shared only with L. platessa. The largely free and widely separated male cerci are a unique character of this species.

\section{Lepidosina gibba (Spuler, 1925), comb. n.}

(Figs 1-4, 31-35, 79)

Leptocera (Scotophilella) gibba Spuler, 1925: 154.

Leptocera (Limosina) gibba: Richards, 1967: 14.

\section{Description}

Head (Figs 1, 2). Upper frons dark brown, with conspicuous pollinose areas; lower frons, antenna, gena and face medium to pale brown; interfrontal bristles in three 


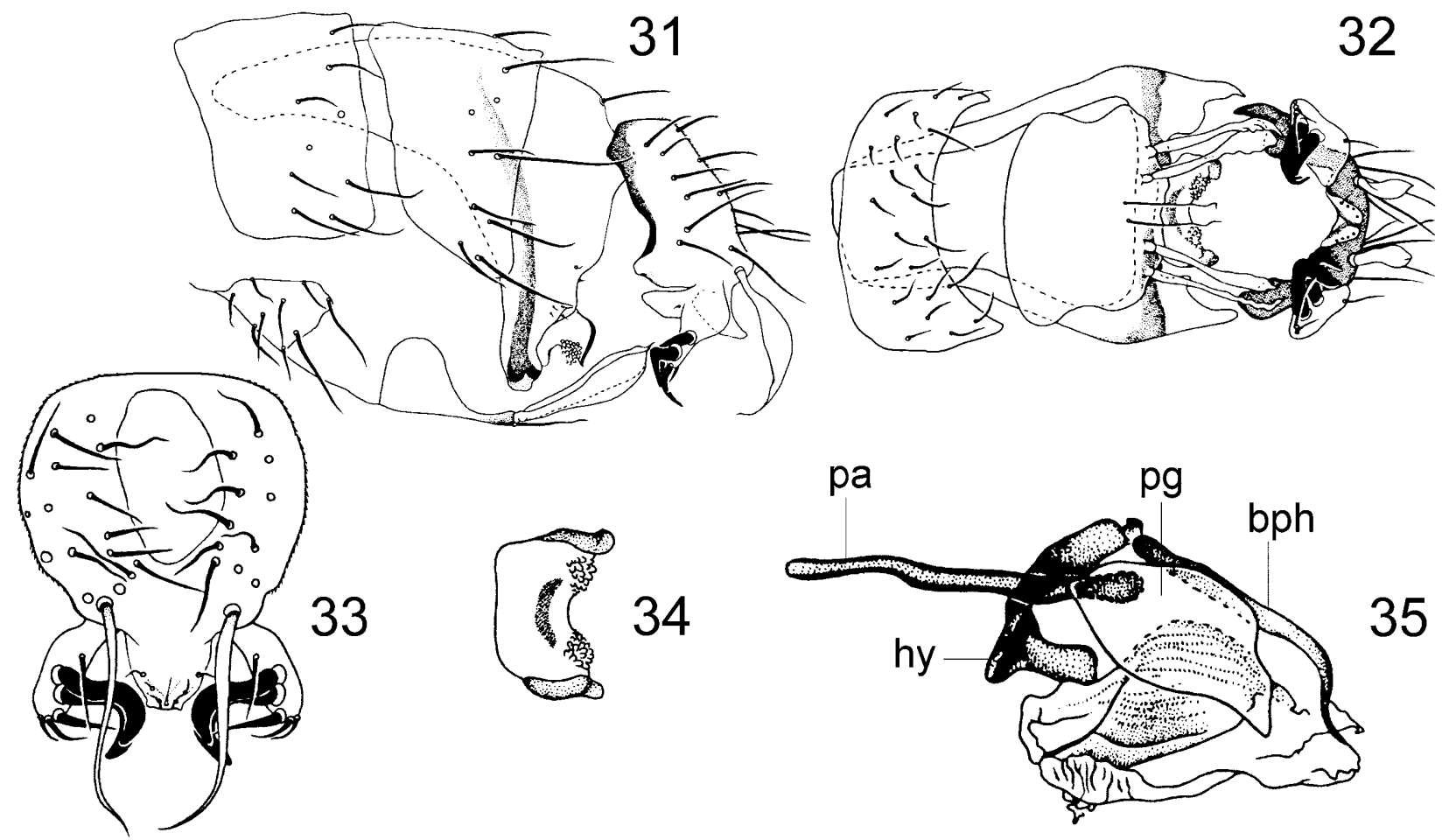

Figs 31-35. Lepidosina gibba (Spuler), male: 31 - abdominal segments 4-5 and terminalia, lateral; 32 - ditto, ventral; 33 - terminalia, posterior; 34 - accessory sclerite of genital pouch; 35 - phallus and associated structures, lateral. bph - basiphallus, hy hypandrium, $\mathrm{pa}$ - phallapodeme, $\mathrm{pg}$ - postgonite.

pairs, upper pair usually shorter than lower pairs, two lowest pairs long, sometimes cruciate.

Thorax (Fig. 4). Acrostichal bristles in 6-8 rows at level of transverse suture, middle acrostichal bristles enlarged, those between anterior dorsocentrals as large as prescutellar acrostichals. Posterior katepisternal bristle at most as long as fore basitarsus, anterior katepisternal minute, sometimes absent.

Legs. Fore femur with two thin dorsal to posterodorsal bristles, posteroventral bristles of distal half extremely short in male, moderately sized in female. Fore tibia of male swollen, flattened and virtually bare ventrally; apical half strongly depressed anterodorsally. Fore tibia of female slender, evenly setulose and not flattened ventrally, distally without anterodorsal emargination. Fore tarsomeres of male strongly flattened, first tarsomere about twice as long as wide, distal four tarsomeres similar in width but shorter, segment three about as long as wide, segment four wider than long. Fore tarsus of female slender, not flattened. Mid femur of male with a V-shaped formation of bristles ventrobasally, those of anteroventral row distinctly stouter and darker, those of posteroventral row more hair-like. Female mid femur without conspicuous bristles ventrobasally. Male mid tibia curved, conspicuously flattened and bare ventrally, posteroventral row of bristles distinct in distal third, bristles becoming increasingly longer and stouter towards apex; apex with one shorter, stout apical bristle and one closely appressed, long, thin hair. Dorsal surface of mid tibia with a small proximal anterodorsal bristle paired with a slightly smaller and more distal proximal posterodorsal bristle, a small anterodorsal at middle, and a strong, distal anterodorsal paired with a slightly longer and more distal posterodorsal bristle. Female mid tibia simple, with dorsal bristles longer than in male, ventral surface not flattened, lacking conspicuous posteroventral row of bristles but with a midventral bristle; ventroapical bristle longer than in male and not accompanied by a thin hair-like bristle. Male hind tibia flattened ventrally, especially in distal half, virtually bare. Second tarsomere of hind leg swollen and twice as long as basitarsus. Female hind tibia simple, neither flattened nor bare ventrally. Second tarsomere of female hind leg somewhat stouter than distal tarsomeres but not swollen as in male.

Wing with costa brown, other veins relatively pale, more so posteriorly. Third costal sector $0.7 \times$ second. Crossveins $\mathrm{r}-\mathrm{m}$ and $\mathrm{dm}-\mathrm{cu}$ separated by slightly more than length of dm-cu. Halter, including stem, pale.

Male terminalia (Figs 3, 31-35). Sternite 5 (Fig. 32) with bare disc and six posterior bristles, middle two small, outer two on each side prominent and scale-like. Synsternite 6-8 (Fig. 31) forming a symmetrical ring, dorsal part with broad anterior apodeme projecting anteriorly under tergites 4-5. Genital pouch with a welldeveloped accessory sclerite (Fig. 34), each half with a broad lateral plate and a compact multi-toothed inner plate. Epandrium short dorsally (Fig. 33); subanal plate subequal in length to perianal area, ventrally with a pair of very long, flat, scale-like bristles similar to those on sternite 5; cerci fused, with a broad, truncate apex. Surstylus (Fig. 33) bilobed; inner lobe subquadrate; outer lobe narrow, prominently projecting laterally, anterolater- 
ally curved and ending in two closely spaced, large, curved, subequal bristles. Phallus short and compact (Fig. 35); basiphallus covering entire dorsal surface of distiphallus, apically drawn out into a slender process. Postgonite broadly lanceolate (Fig. 35).

Female terminalia similar to L. angusticercus except for the following differences: Cerci more slender; large flattened preapical bristle more slender as well; dorsal surface nearly bare or only laterally with a few microtrichia, microtrichose area separated by bare area from microtrichose patch of tergite 10 . Sternite 8 about $0.8 \times$ as wide as sternite 10 , with median pair of setulae near posterior margin $1.3-3.4 \times$ as far apart as setulae on each side. Anteroventral margin of sternite 10 acutely produced forward at middle, medially divided by a strip of noticeably weaker sclerotization that becomes gradually more obscure posteriorly. Posterior margin of sternite 10 between medial pair of setulae microtrichose (as in $L$. angusticercus but different from closely related $L$. inaequalis). Spermathecae (2+1) small (Fig. 79), the larger single spermatheca 55-70 $\mu \mathrm{m}$ long (spermatheca size apparently influenced by body size); transverse ridging of surface weaker; individual ducts of paired spermathecae extremely short. In one specimen paired accessory glands were observed as described for L. rutricauda below.

Type material. Holotype $\widehat{\delta}$ (not examined, USNM) and 2 paratypes (1 0 examined, USNM). Jamaica. Battersea, ii.1910, H. Thaxter.

Notes on the type series: Spuler (1925) notes that the types were mounted from alcohol and had lost most of their original color and bristles. We have examined one paratype, and it has almost no bristles, no left wing, no hind legs and no abdomen. The specimen bears a blue label saying "sex unknown", however the mid leg is intact and is itself enough to confirm the identity and sex of the specimen.

Other material examined. Other material examined. U.S.A. Florida, Highlands Co., Archbold Biological Station (20ิ, 3 \% , DEBU, USNM, CASC); Highlands Hammock State Park (30, $1+$, DEBU); St. Lucia Co. (1ㅇ, DEBU); Broward Co., Big Cypress Reservation (1 9 , DEBU). Jamaica. Hardwar Gap (1 $\delta^{*}$ USNM); Annotto Bay (1 $\delta$, USNM). Dominican Republic. Puerto Plata $(1 \hat{\delta}, 1 \%$, DEBU; $\hat{\sigma}$ is "Barcode of Life" specimen DEBU0061); La Cienaga (1 + , DEBU); Hato Mayor, Parque los Haitises $(30$, $4 q, \mathrm{CMNH}$; 10 is "Barcode of Life" specimen DEBU0060). Haiti. Baie de Chouchou (1 ठิ, USNM).

Distribution. United States (Florida), Jamaica, Haiti and Dominican Republic.

Discussion. Lepidosina gibba is the only species with scale-like bristles on male sternite 5 that has retained the anterodorsal bristle at mid length of the male mid tibia. Only this species and L. inaequalis have scale-like bristles both on sternite 5 and on the epandrium. These two similar species differ in small details of the male genitalia (shape of cerci and postgonites, armature of surstylus).

Lepidosina inaequalis (Malloch, 1914), comb. n. (Figs 36-42)

Leptocera (Limosina) inaequalis Malloch, 1914: 21.

\section{Description}

Head. Upper frons dark brown, with conspicuous pollinose areas; lower frons, antenna, gena and face pale brown to yellow; interfrontal bristles in three pairs, upper pair usually shorter than lower pairs, two lowest pairs long, sometimes cruciate.

Thorax. Acrostichal bristles in 6-8 rows at level of transverse suture, middle acrostichal bristles enlarged, those between anterior dorsocentrals as large as prescutellar acrostichals. Posterior katepisternal bristle at most as long as fore basitarsus, anterior katepisternal small.

Legs. Fore femur with two dorsal to posterodorsal bristles, posteroventral bristles of distal half extremely short in male, moderately sized in female. Fore tibia of male swollen, flattened and virtually bare ventrally; apical half strongly depressed anterodorsally. Fore tibia of female slender, evenly setulose and not flattened ventrally, distally without anterodorsal emargination. Fore tarsomeres of male strongly flattened, first tarsomere about twice as long as wide, distal four tarsomeres similar in width but shorter, penultimate tarsomere twice as wide as long. Mid femur of male with a V-shaped formation of bristles ventrobasally, those of anteroventral row distinctly stouter and darker, those of posteroventral row more hair-like. Female mid femur without conspicuous bristles ventrobasally. Dorsal surface of mid tibia with a small, proximal anterodorsal bristle paired with a slightly smaller and more distal proximal posterodorsal bristle and a strong, distal anterodorsal paired with a slightly longer and more distal posterodorsal bristle, female also with an anterodorsal at middle. Male mid tibia curved, conspicuously flattened and bare ventrally, posteroventral row of bristles distinct in distal third, bristles becoming increasingly longer and stouter towards apex; apex with one shorter, stout apical bristle and one closely appressed, long, thin hair. Female mid tibia simple, with dorsal bristles longer than in male, ventral surface not flattened, lacking conspicuous posteroventral row of bristles but with a midventral bristle; ventroapical bristle longer than in male and not accompanied by thin, hair-like bristle. Male hind tibia flattened ventrally, especially in distal half, virtually bare. Second tarsomere of hind leg swollen and twice as long as basitarsus. Female hind tibia simple, neither flattened nor bare ventrally. Second tarsomere of female hind leg somewhat stouter than distal tarsomeres but not swollen as in male.

Wing with costa brown, other veins relatively pale, more so posteriorly. Third costal sector $0.7 \times$ second. Crossveins $\mathrm{r}-\mathrm{m}$ and $\mathrm{dm}-\mathrm{cu}$ separated by more than length of dm-cu. Halter, including stem, pale.

Male terminalia (Figs 36-42). Sternite 5 (Fig. 37) with bare disc and six bristles at posterior margin, middle pair small, outer pairs long and scale-like. Synsternite 6-8 (Fig. 36) forming a symmetrical ring, dorsal part with broad anterior apodeme projecting anteriorly under tergites 4-5. Genital pouch with a well-developed accessory sclerite (Fig. 40), bearing a compact, multi-toothed plate on each side. Epandrium short dorsally (Fig. 39); subanal plate slightly shorter than perianal area, with long bristles, 


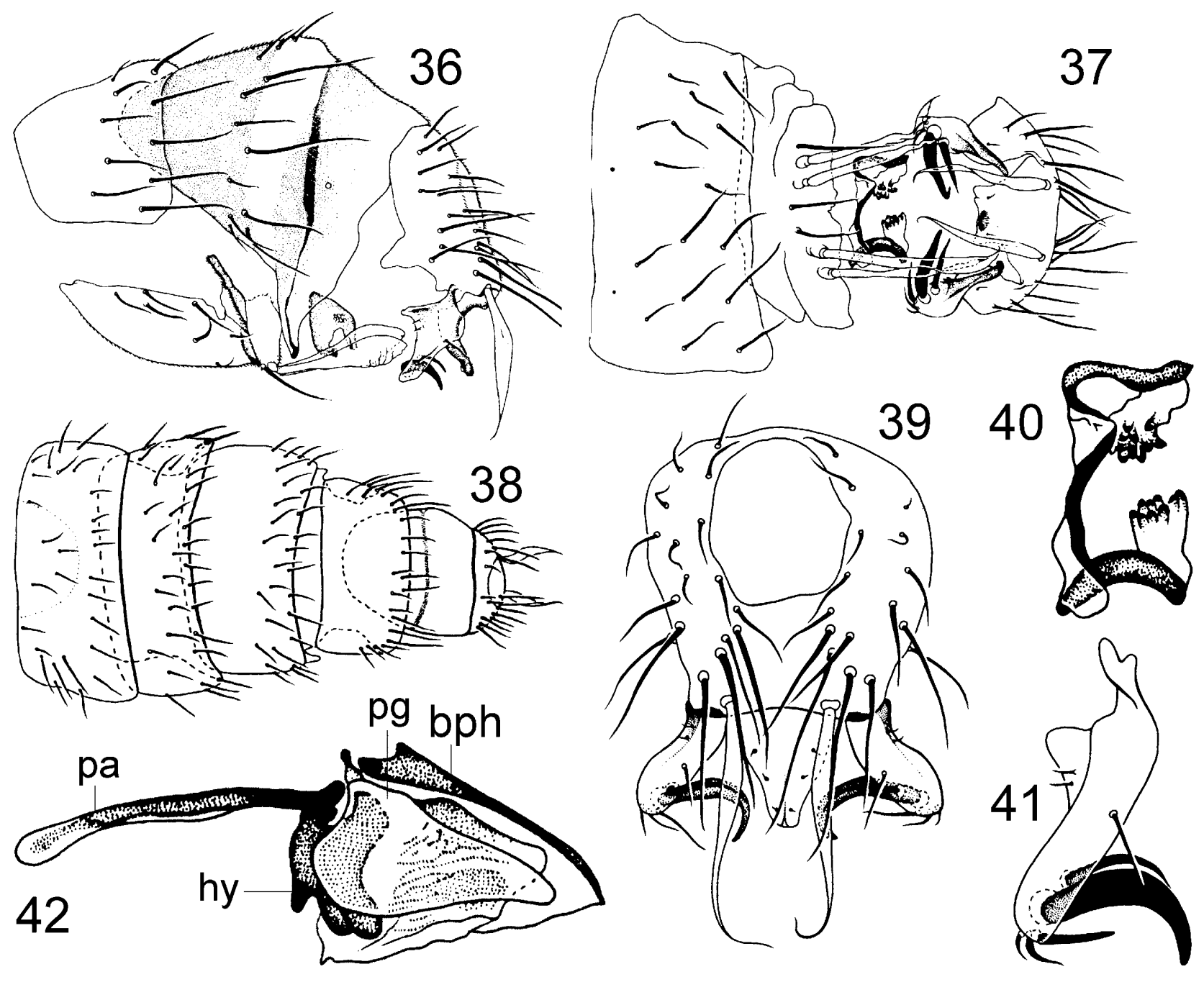

Figs 36-42. Lepidosina inaequalis (Malloch), male: 36 - abdominal segments 4-5 and terminalia, lateral; 37 - ditto, ventral; 38 abdomen, dorsal; 39 - terminalia, posterior; 40 - accessory sclerite of genital pouch; 41 - left surstylus, lateral; 42 - phallus and associated structures, lateral. bph - basiphallus, hy - hypandrium, pa - phallapodeme, $\mathrm{pg}$ - postgonite.

longest pair flattened and scale-like; cerci basally fused and distally contiguous, distally tapered with narrowly rounded apex. Surstylus (Fig. 41) bilobed, inner lobe subquadrate; outer lobe narrow, prominently projecting laterally, anterolaterally curved and ending in two closely spaced, large, curved, bristles; posterior bristle much smaller than anterior. Phallus short and compact (Fig. 42), with basiphallus forming a dark, tapered upper surface of phallus, extending to apex of distiphallus. Postgonite broadly triangular (Fig. 42), almost as long as basiphallus.

Female terminalia practically indistinguishable from $L$. gibba. The reliability of the following distinguishing characters requires further study: Sternite 8 only about $0.5 \times$ as wide as sternite 10 , with median pair of setulae near posterior margin $1.2-2.5 \times$ as far apart as setulae on each side. Posterior margin of sternite 10 between medial pair of setulae with very few microtrichia (usually just inside the setulae) or practically bare. Medial weakly sclerotized strip of sternite 10 sometimes poorly defined. Spermathecae $(2+1)$ larger than in L. gibba (single sper- matheca ca. 70-75 $\mu \mathrm{m}$ long), with somewhat stronger ridging.

Type material. Holotype $\widehat{o}$ (ANSP). Costa Rica. Cartago, 10.x.1909, swept over mud, [P.P. Calvert]. Paratype (sex not indicated by Malloch). Same data except 3.i.1910 (ANSP, not examined).

Other material examined. United States. Alabama, Kushla, (10, SEMC). Mexico. Baja California Sur, Hwy 1 at $\mathrm{km} 71.5$ (1,+ CASC); Sonora, Alamos (1 9, CASC); Jalisco, $20 \mathrm{mi} \mathrm{W}$ of

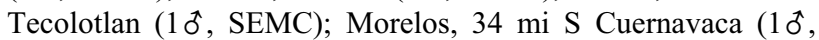
CNCI); San Luis Potosí, Tamasunchale (1 + , CASC). Belize. San Ignacio, Maya Mountain Lodge (1 $q$, DEBU); Xunantunich (4t), 9ㅇ, DEBU; $2 \hat{\sigma}$ are "Barcode of Life" specimens DEBU0058 and 59). El Salvador. Los Chorros (10, CASC). Costa Rica. Cartago, Turrialba (1 + , CASC); Puntarenas R.F., Golfo Dulce (1 + , INBC); Puntarenas, Reserva Biologica Carara

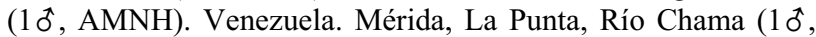
IZAV). Tentatively identified, unassociated female: Ecuador. Galápagos Is., San Cristóbal (1 \&, DEBU).

Distribution. United States (Alabama), Mexico, Belize, El Salvador, Costa Rica and Venezuela. One female from the Galápagos Is. is indistinguishable from $L$. inaequalis and could be this species or a closely related, unrecognised species. 


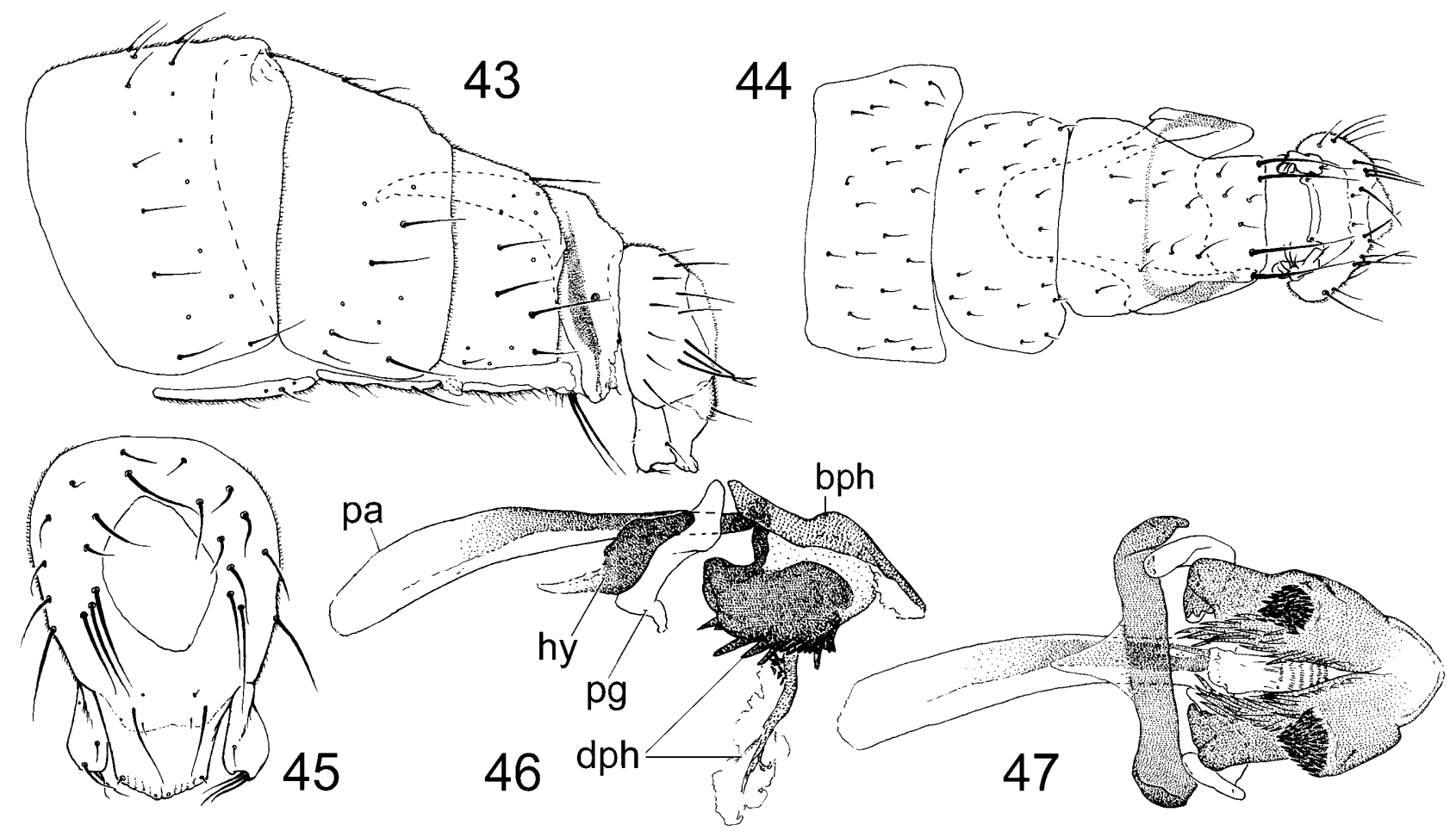

Figs 43-47. Lepidosina multispinulosa sp. n., male: 43 - abdominal segments 3-5 and terminalia, lateral; 44 - ditto, ventral; 45 terminalia, posterior; 46 - phallus and associated structures, lateral; 47 - ditto, ventral. bph - basiphallus, dph - distiphallus, hy hypandrium, pa - phallapodeme, pg - postgonite.

Discussion. Lepidosina inaequalis is very close to $L$. gibba, a Caribbean species, from which it differs most obviously in lacking the anterodorsal bristle near mid length of the male mid tibia, and in having unequal surstylar bristles. The latter character seems to be reflected in the specific epithet "inaequalis" but Malloch (1914) makes no mention of the surstylus in his description of this species. Apparently he based the name on the unequal length of the second and third costal sectors, a character that he used to separate L. inaequalis from $\mathrm{Opa}$ cifrons bisecta (Malloch), which was described in the same paper (see couplet 19 of Malloch's key, p. 11).

\section{Lepidosina multispinulosa Marshall \& Buck, sp. n.} (Figs 43-47)

\section{Description}

Male only (female unknown). Head mostly black with conspicuous pollinose areas on frons; lower frons reddish, interfrontal bristles in four pairs, middle three pairs larger than lower pair.

Thorax. Acrostichal bristles in ca. 6 rows at level of transverse suture, middle acrostichal bristles slightly to moderately enlarged, prescutellar pair not strongly enlarged. Katepisternal bristles small, posterior one about half as long as fore basitarsus, anterior one extremely small, virtually absent.

Legs. Fore femur with two dorsal to posterodorsal bristles, posteroventral bristles of distal half extremely short. Fore tibia flattened ventrally, bare basally, sparsely setulose distally, deeply excavated on distal half. Fore tarsomeres conspicuously broad and flat and consecutively shorter (basal tarsomere twice as long as wide, second nearly as long as first, distal tarsomeres slightly wider than long). Mid femur ventrobasally with a group of 5-6 setulae in a rectangular formation, these darker and somewhat stouter than other setulae. Posteroventral row of setulae hardly discernable, not in an arcuate row (see $L$. rutricauda). Mid tibia curved, ventral surface flat and bare over basal $3 / 4$, very weak rows of anteroventral and posteroventral bristles converging distally towards cluster of preapical bristles; apicoventral bristle short, length not exceeding width of mid basitarsus, accompanied by one long and one medium-sized thin, hair-like bristle. Mid tibia with three subequal anterodorsal (proximal, mid, distal) bristles and two very small posterodorsal bristles inserted distal to corresponding anterodorsal bristles. Hind tibia ventrally flattened and largely bare (except distally where antero- and posteroventral rows of hairs converge), apicoventrally only with short hairs. Second tarsomere of hind tarsus strongly swollen.

Wing with uniformly pale brown veins, crossveins $\mathrm{r}-\mathrm{m}$ and dm-cu separated by twice length of dm-cu (four times length of $\mathrm{r}-\mathrm{m}$ ). Third costal sector $0.8 \times$ length of second costal sector. Halter stem white, knob pale brown.

Male terminalia (Figs 43-47). Sternite 5 long-trapezoid with setulose disc (Fig. 44), posterior margin nearly straight, with two pairs of long bristles. Synsternite 6-8 (Figs 43, 44) U-shaped (ventrally open), bare, dorsal part with broad anterior apodeme projecting below tergite 5 and hind margin of tergite 4 (apodeme apparently undeveloped in paratype). Genital pouch with a simple U-shaped, asymmetrically placed (shifted towards left 


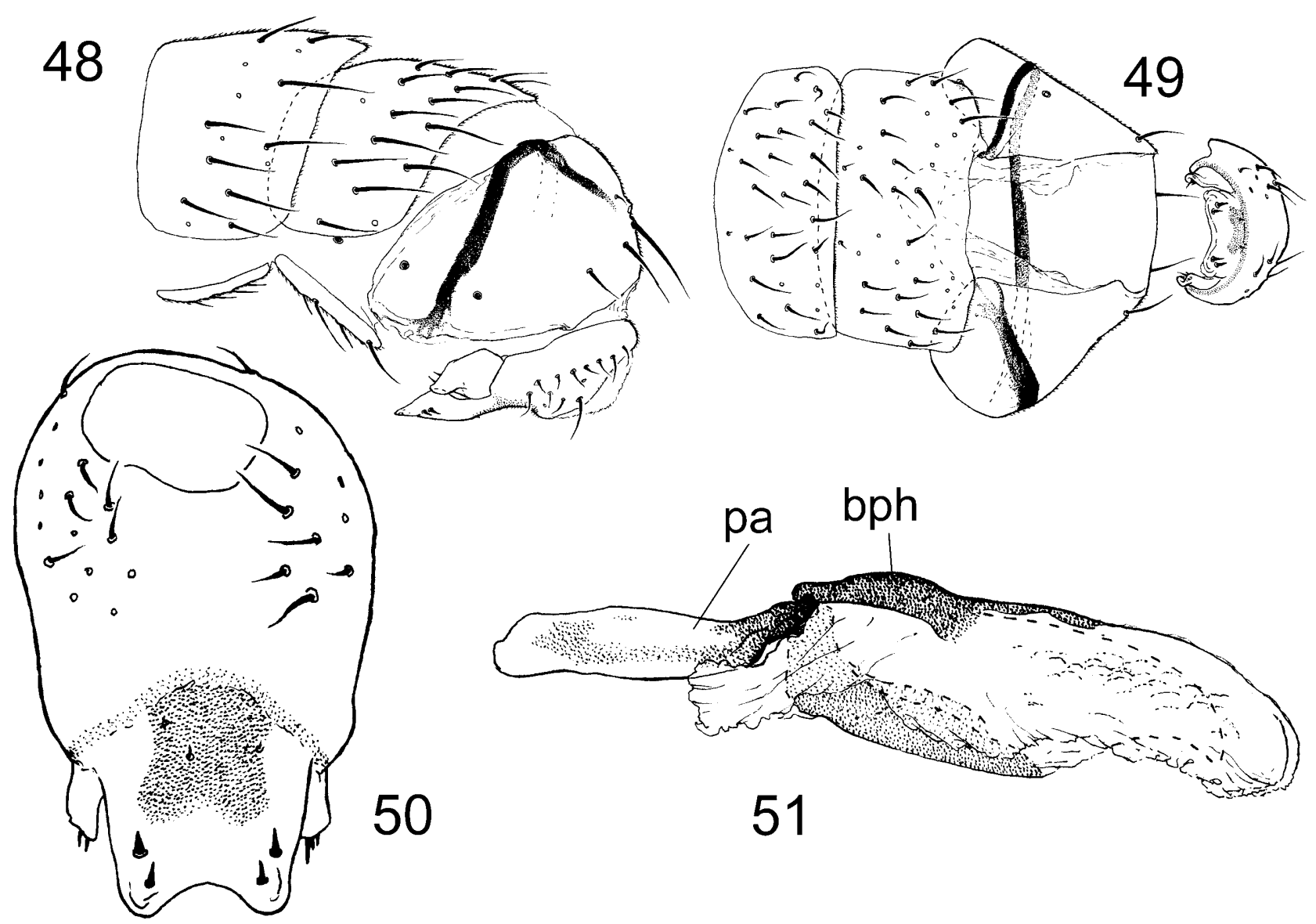

Figs 48-51. Lepidosina platessa sp. n., male: 48 - abdominal segments 4-5 and terminalia, lateral; 49 - ditto, ventral; 50 - terminalia, posterior; 51 - phallus and associated structures, lateral (postgonite omitted). bph - basiphallus, pa - phallapodeme.

side) accessory sclerite, and with an apparently eversible, membranous sac with scale-like surface sculpture. Epandrium (Fig. 45) with broad subanal plate continuous with broad, largely fused cerci; subanal plate with a pair of long bristles; both subanal plate and cerci with pairs of short, stout bristles; combined subanal plate plus cerci slightly curved posteriorly towards apex. Surstylus subrectangular (Figs 43, 45), widening apically; apex seemingly truncate but actually with a delicate, nearly transparent, triangular flap; hind margin with one, anteroventral corner with several bristles in a short row. Hypandrium transverse (Fig. 47), moderately sclerotized, with small remnant of a anteromedial apodeme. Basiphallus plate-like, extending over posterodorsal surface of phallus (Fig. 46), inconspicuous and weakly sclerotized except near articulation with phallapodeme. Distiphallus with numerous spines of various lengths (Fig. 47); laterally towards base on each side with a circular patch of short, extremely crowded spines; paramedially from base to apex with a series of less crowded spines, spines increasing in size from base to middle, longest ones from middle to apex; spines much shorter and less sclerotized than in the related L. rutricauda. Postgonite pale (Fig. 46), unusually elongate, angulate near apex in lateral view, curved medially in posterior view.

Type material. Holotype $\delta$. Ecuador, Napo, Yasuní National Park, Yasuní Research Station, 3.-20.xi.1998, rain forest, Mal- aise trap, Pape \& Viklund, debu00117076 (ZMUC). Paratype §. Peru. Madre de Dios, Manú National Park, Cocha Cashu Biological Station, 380 m, 23.-30.viii.1986, Malaise trap, D.C. Darling, ROM863569 (ROME).

Note: One female from the same locality as the paratype is indistinguishable from females of $L$. rutricauda, and probably belongs to that species (see there) even though we have not seen any L. rutricauda males from Peru.

Etymology. The name refers to the conspicuous spinulose armature of the distiphallus.

Distribution. Ecuador and Peru east of the Andes.

Discussion. This species is obviously closely related to L. rutricauda, with which its shares the same, very distinctive, general structure of the phallus (distiphallus armed with groups of forwardly directed spines). Lepidosina multispinulosa can be readily separated from $L$. rutricauda based on the following characters: male mid femur simple (not ventrally emarginate), synsternite 6-8 open ventrally, its anterodorsal apodeme short, only reaching hind margin of tergite 4 (synsternite not forming a closed ring, apodeme not extending to hind margin of tergite 3), genital pouch with a simple U-shaped accessory sclerite (not with a sclerotized digitate process), postgonite elongate (not short), distiphallus with a conspicuous, circular patch of short spines on each side (spines longer and not grouped in circular patches in $L$. rutricauda). 


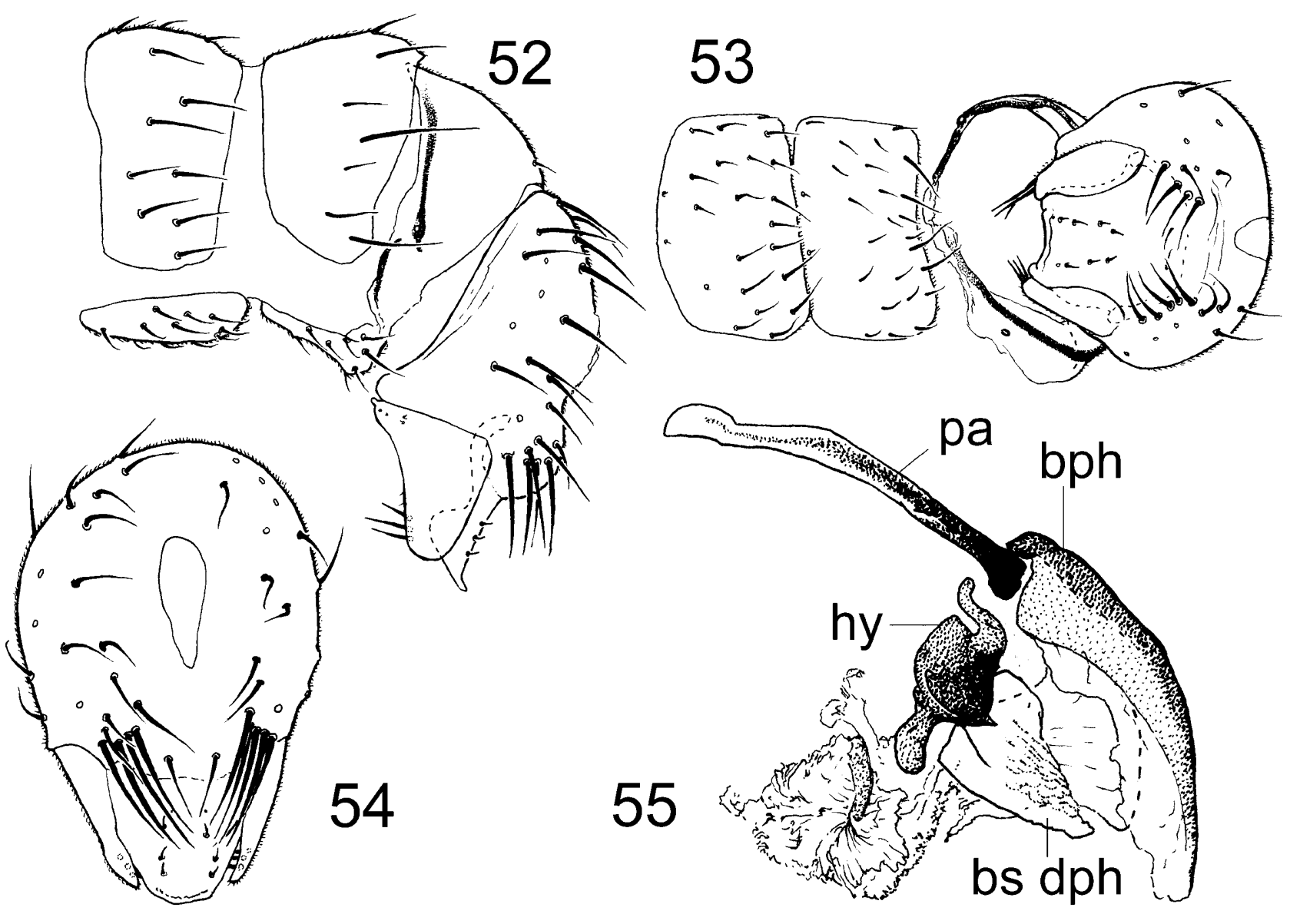

Figs 52-55. Lepidosina proxineura sp. n., male: 52 - abdominal segments 4-5 and terminalia, lateral; 53 - ditto, ventral; 54 - terminalia, posterior; 55 - phallus and associated structures, lateral. bph - basiphallus, bs dph - basal sclerite of distiphallus, hy hypandrium, pa - phallapodeme.

\section{Lepidosina platessa Marshall \& Buck, sp. n.}

(Figs 48-51)

\section{Description}

Male only (female unknown). Head mostly black with conspicuous pollinose areas on frons, lower frons reddish; interfrontal bristles in four pairs, upper three pairs very large with apices of bristles meeting. Anterior upturned bristle of gena shorter than in other species, only half as long as vibrissa.

Thorax. Acrostichal bristles in 8-10 rows at level of transverse suture, middle acrostichals only moderately enlarged, shorter than prescutellar pair. Thoracic bristles relatively strong. Both dorsal katepisternal bristles well developed, posterior bristle about as long as fore basitarsus, anterior one over half as long as posterior one.

Legs. Fore femur with $2-5$ dorsal to posterodorsal bristles; posteroventral bristles of distal half small (i.e., probably distinctly shorter than in female). Fore tibia with apical half distinctly depressed anterodorsally. Fore tarsomeres strongly flattened, gradually decreasing in length from first to fourth, first tarsomere about twice as long as wide, fourth wider than long. Male mid leg showing almost none of the usual sexually dimorphic characters except for the lack of the midventral bristle; otherwise probably nearly identical to the unknown female. Mid femur ventrobasally without crowded and conspicuously modified bristles, those of anteroventral row only slightly stouter towards base, those of anteroventral row becoming longer and more erect. Mid tibia neither conspicuously flattened nor curved, antero- and posteroventral rows of bristles unmodified (i.e. neither stronger nor weaker than usual), closely approximated in distal third, apex with only a single strong ventral bristle (longer than in any other species and not accompanied by 1-2 thin, hair-like bristles); anteroapical and posteroapical bristles present as on apices of tarsomeres. Dorsal surface of mid tibia with a proximal anterodorsal bristle paired with a slightly smaller and more distal proximal posterodorsal bristle, an anterodorsal at middle, and a strong, distal anterodorsal paired with a slightly longer and more distal posterodorsal bristle. All bristles unusually long for a male, distal pair longer than width of tibia. Hind leg simple. Hind tibia densely setulose and not flattened ventrally, apicoventrally without enlarged hairs. Hind leg with second tarsomere stouter than distal tarsomeres but not distinctly swollen.

Wing very similar to L. evanescens (Fig. 6), with a narrow but almost parallel-sided alula (in contrast to the narrow-triangular alula of congeners); veins pale brown. Third costal sector $0.8 \times$ length of second costal sector. 


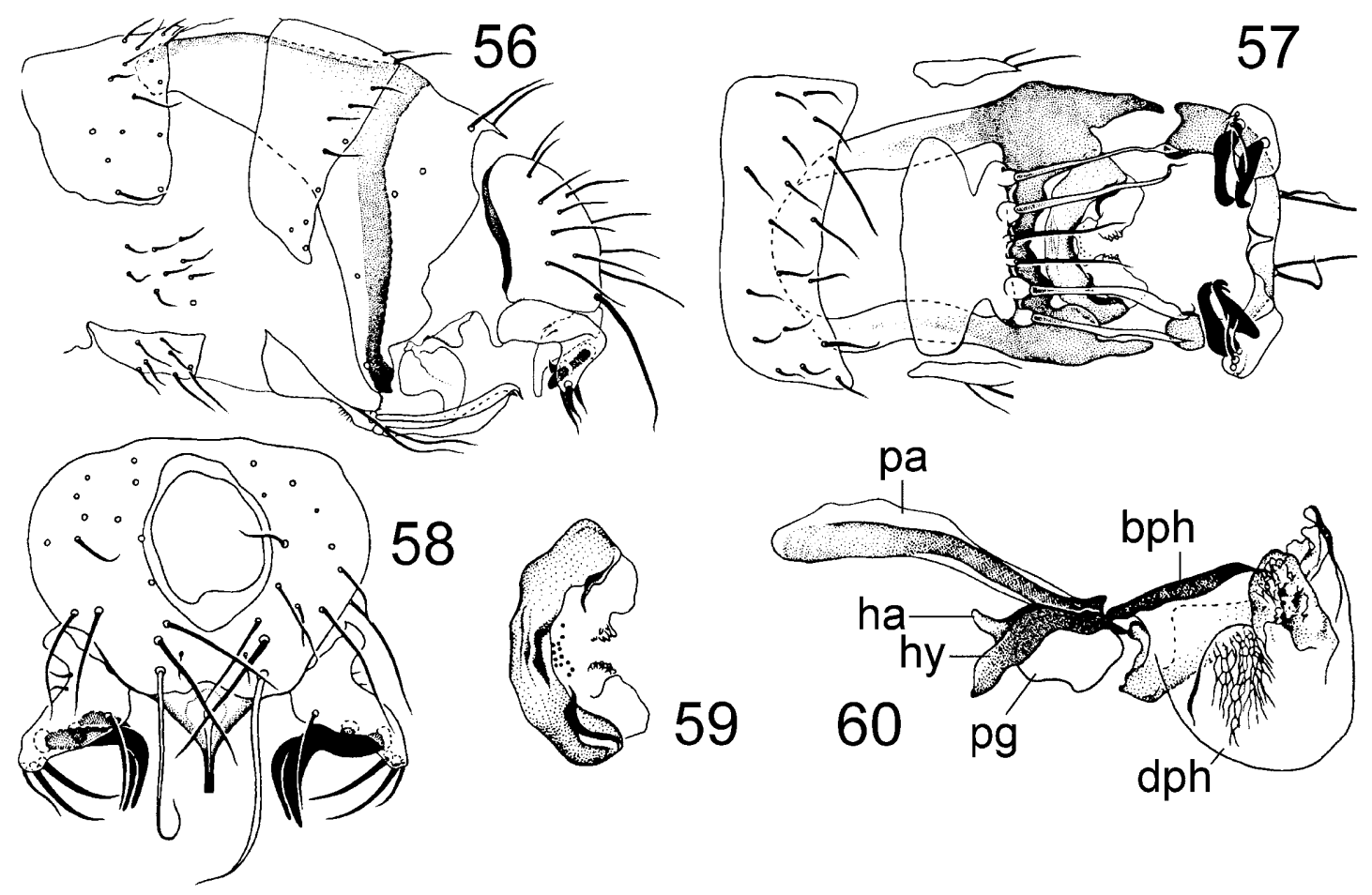

Figs 56-60. Lepidosina quadrisquamosa sp. n., male: 56 - abdominal segments 4-5 and terminalia, lateral; 57 - ditto, ventral; 58 - terminalia, posterior; 59 - accessory sclerite of genital pouch; 60 - phallus and associated structures, lateral. bph - basiphallus, dph - distiphallus, ha - hypandrial apodeme, hy - hypandrium, pa - phallapodeme, pg - postgonite.

Crossvein dm-cu absent; vein $\mathrm{M}$ except for a short tubular stump fold-like beyond $\mathrm{r}-\mathrm{m} ; \mathrm{CuA}_{1}$ also fold-like beyond bend near mid-length of distally open discal cell. Halter pale, stem slightly darker than knob.

Male terminalia (Figs 48-51). Sternite 5 subquadrate (Fig. 49), unmodified, evenly haired. Synsternite 6-8 symmetrical (Figs 48, 49), broadly open ventrally (not forming a ring); dorsal part broad, sparsely setulose and with three pairs of long bristles at hind margin, lacking anterior apodeme. Epandrial complex (Fig. 50) extraordinary, with unusually small perianal area; subanal plate and fused cerci forming an elongate, distally bilobed plate over twice as long as remainder of epandrium. Cerci poorly differentiated from subanal plate, their apices widely separated by a shallow emargination; each bearing two short, stout, dorsally directed bristles. Hypandrium simple, transverse, largely desclerotized except laterally where it meets surstyli. Surstylus small (Fig. 48), pale, distal margin with a row of small bristles. Basiphallus forming a flat, quadrate plate with bilobed distal margin (Fig. 51); distiphallus forming a pair of plates; phallapodeme unusually short. Postgonite longer than wide (not illustrated because illustration would require destructive dissection). Ejaculatory apodeme relatively large but weakly sclerotized, shield-like with six sensory pores.

Type material. Holotype $\widehat{\delta}$. Bolivia. Santa Cruz. Portrerillo, Terevinto, 18.-20.ix.1996, W. Rossi, debu00101270 (DEBU).

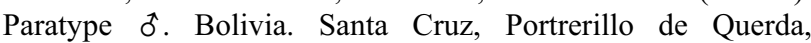
$17^{\circ} 40.49^{\prime} \mathrm{S}, 63^{\circ} 27.36^{\prime} \mathrm{W}, 4 .-7 . i v .1998$, H. \& A. Howden (DEBU).

Etymology. The specific epithet refers to the strikingly flattened fore tarsomeres and fore tibial apex.
Distribution. At present only known from eastern Bolivia.

Discussion. The mid tibial chaetotaxy of Lepidosina platessa males is similar to the mid tibial chaetotaxy of females of other Lepidosina species (large apicoventral bristle, large anterodorsal bristle at middle, not flattened, not curved) except for the lack of a midventral bristle. The plesiomorphic male tibia, combined with the unmodified hind tarsus, separates $L$. platess $a$ from the rest of the genus.

\section{Lepidosina proxineura Marshall \& Buck, sp. n.}

(Figs 52-55)

\section{Description}

Male only (female unknown). Head pale brown with inconspicuous pollinose areas; interfrontal bristles in four pairs, middle two pairs larger than upper and lower.

Thorax. Acrostichal bristles in ca. 6 rows at level of transverse suture, middle acrostichal bristles enlarged, longer than prescutellar pair. Katepisternal bristles small, posterior one just over half as long as fore basitarsus, anterior one small or minute.

Legs. Fore femur with one posterodorsal bristle near middle; posteroventral bristles of distal half extremely short. Fore tibia swollen, flattened and largely bare ventrally, apical 2/5 distinctly depressed anterodorsally. Fore tarsomeres strongly flattened, first tarsomere about twice as long as wide, tarsomeres two and three subequal in length and width, tarsomeres four and five wider than long. Mid femur with a V-shaped formation of bristles ventrobasally, those of anteroventral row distinctly stouter and darker, those of posteroventral row elongate, 

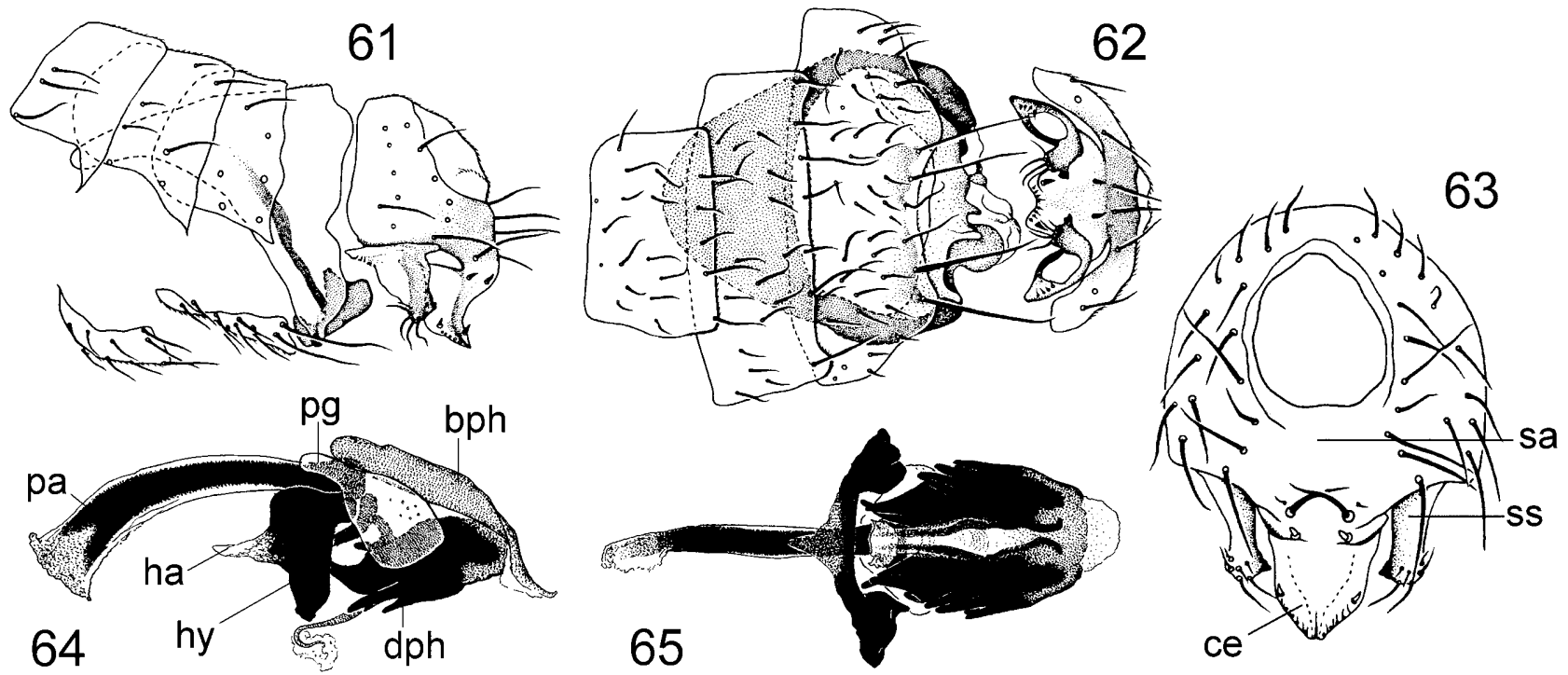

Figs 61-65. Lepidosina rutricauda sp. n., male: 61 - abdominal segments 3-5 and terminalia, lateral; 62 - ditto, ventral; 63 - terminalia, posterior; 64 - phallus and associated structures, lateral; 65 - ditto, ventral. bph - basiphallus, ce - cerci, dph - distiphallus, ha - hypandrial apodeme, hy - hypandrium, pa - phallapodeme, pg - postgonite, sa - subanal plate, ss - surstylus.

hair-like and erect. Mid tibia curved; ventral surface flattened, bare; bristles of antero- and posteroventral rows minute, latter virtually absent; ventroapical bristle short and stout, accompanied by a long, closely appressed, thin, hair-like bristle. Dorsal surface of mid tibia with two anterodorsal bristles paired with two posterodorsal bristles; distal bristles long and almost at same level (posterodorsal slightly longer than anterodorsal); proximal bristles staggered and small (posterodorsal shorter than anterodorsal). Hind tibia ventrally flattened and bare except apically where antero- and posteroventral rows of hairs converge; apex with two long, thin, ventral hairs; hairs just above apex also longer than usual. Basal two tarsomeres of hind tarsus swollen and distinctly flattened ventrally, anteroventrally with hairs that are longer than usual.

Wing with veins very pale brown, crossveins $\mathrm{r}-\mathrm{m}$ and $\mathrm{dm}$-cu closely approximated and almost at same level; third costal sector $0.8 \times$ as long as second. Halter white.

Male terminalia (Figs 52-55). Sternite 5 subquadrate (Fig. 53), with setulose disc and two pairs of only slightly enlarged posterior bristles. Synsternite 6-8 symmetrical (Figs 52, 53), forming a complete ring but midventral part of ring very weak; dorsal part largely bare with but one pair of short bristles posteriorly, lacking anterior apodeme; subanal plate broad, flanked by a prominent row of long bristles on each side. Cerci entirely fused to form a narrow, tongue-like lobe, apex broadly rounded, disc with two longitudinal rows of hairs. Surstylus pale (Fig. 52), triangular with broadly rounded apex, anterior margin with a row of three bristles. Basiphallus forming a flat plate along entire posterior surface of phallus (Fig. 55). Postgonites not visible in the only paratype dissected (the internal genitalia were studied without removal from the abdomen and some details are not clear) basal distiphallus sclerite broad, surface distinctly striate, integrated with base of the compact phallic complex.
Type material. Holotype $\delta$. Brazil. Rio de Janeiro, Rio de Janeiro, Represa dos Ciganos, 22.-24.i.1990, Malaise trap, S.A. Marshall (MZSP). Paratype ô. Brazil. Rio de Janeiro, Rio de Janeiro, Pedra de Ituana (a private residential complex), 21.-24.i.1990, pans near lagoon, S.A. Marshall (DEBU).

Etymology. The specific epithet refers to the approximated crossveins $\mathrm{r}-\mathrm{m}$ and dm-cu.

Distribution. At present only known from southeastern Brazil.

Discussion. This species is easily distinguished from all congeners by the closely approximated crossveins and by the mid tibia, which lacks a middle anterodorsal bristle. The enlarged ventroapical hairs of the male hind tibia are also characteristic (shared only with $L$. cubensis). Both specimens of this species were collected within metropolitan Rio de Janeiro, albeit in very different habitats (a dry residential area and a humid forested area).

\section{Lepidosina quadrisquamosa Marshall \& Buck, sp. n.}

(Figs 56-60, 75, 76, 81)

\section{Description}

Head. Upper frons dark brown, with conspicuous pollinose areas; lower frons, antenna, gena and face pale brown to yellow; interfrontal bristles in three pairs, middle pair largest and two lowest pairs with apices of bristles meeting.

Thorax. Acrostichal bristles in ca. 6 rows at level of transverse suture, middle acrostichal bristles enlarged, those between anterior dorsocentrals as large as prescutellar acrostichals. Posterior katepisternal bristle at most as long as fore basitarsus, anterior katepisternal small.

Legs. Fore femur with two dorsal to posterodorsal bristles, posteroventral bristles of distal half extremely short in male, moderately sized in female. Fore tibia of male swollen, flattened and virtually bare ventrally; apical half strongly depressed anterodorsally. Fore tibia of female slender, evenly setulose and not flattened ventrally, dis- 

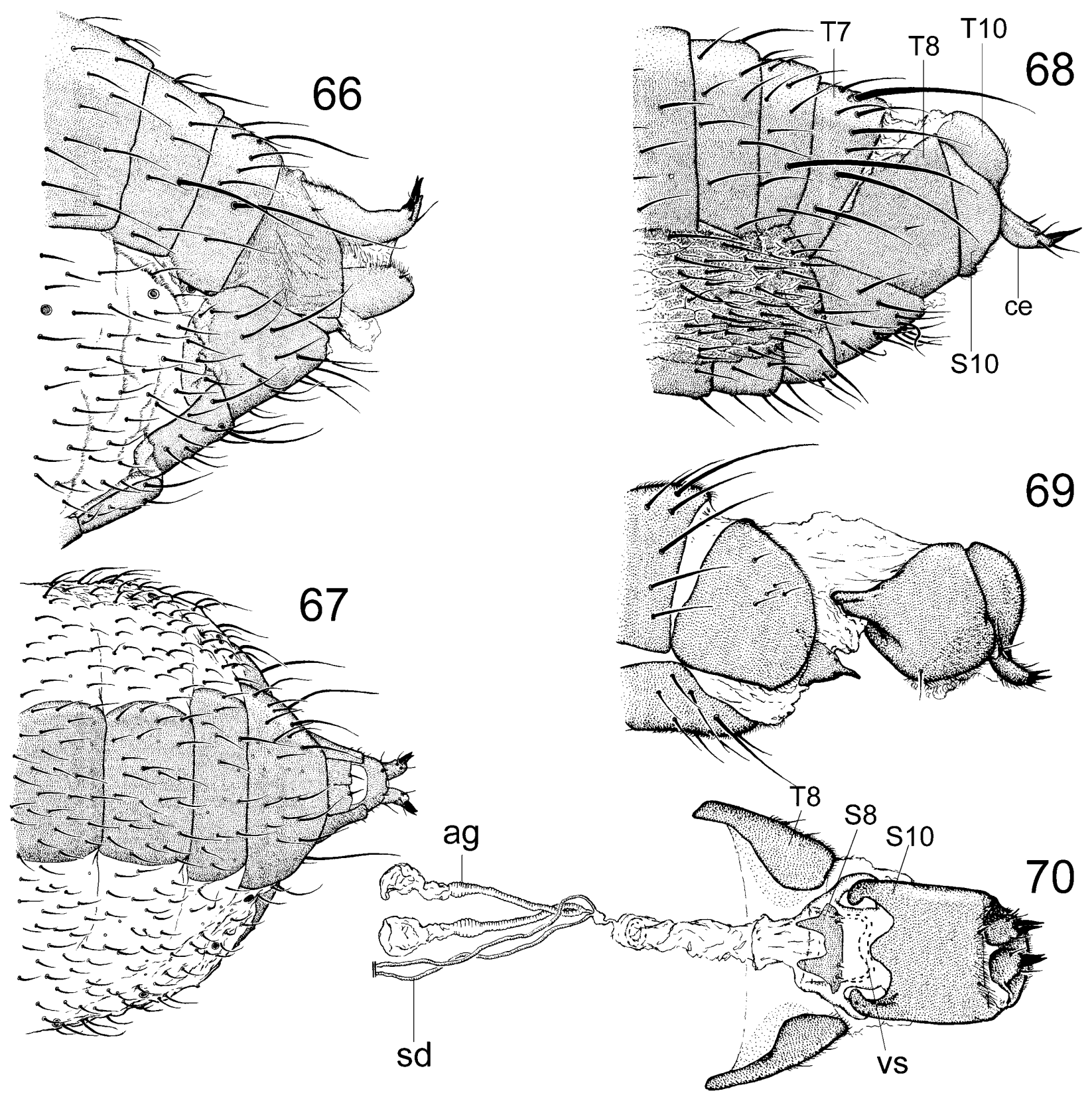

Figs 66-70. Lepidosina females. L. cubensis sp. n., abdominal segments 5-7 and terminalia: 66 - lateral; 67 - ventral. L. rutricauda sp. n., abdomen and terminalia: 68 - segments 5-7 and terminalia, lateral; 69 - segment 7 and terminalia (segment 10 and cerci extended), lateral; 70 - terminalia and internal genitalia, ventral. ag - accessory gland, ce - cercus, $\mathrm{S}$ - sternite, sd - spermathecal duct, $\mathrm{T}$ - tergite, vs - vaginal sclerite (?).

tally without anterodorsal emargination. Fore tarsomeres of male strongly flattened, first two tarsomeres similar and about twice as long as wide, third tarsomere about as wide as long, distal two tarsomeres very broad, almost twice as wide as long. Mid femur of male with a V-shaped formation of bristles ventrobasally, those of anteroventral row distinctly stouter and darker, those of posteroventral row more hair-like. Female mid femur without conspicuous bristles ventrobasally. Male mid tibia curved, conspicuously flattened and bare ventrally, posteroventral row of bristles distinct in distal third, bristles becoming increasingly longer and stouter towards apex; apex with one shorter stout apical bristle and two closely appressed, long, thin hairs; one small anterodistal bristle. Dorsal surface of mid tibia with a small proximal anterodorsal bristle (sometimes absent in male) paired with a slightly smaller and more distal proximal posterodorsal bristle, and with a strong, distal anterodorsal paired with a slightly longer and more distal posterodorsal bristle, female also with an anterodorsal at middle. Female mid tibia simple, with dorsal bristles longer than in male, ventral surface not flattened, lacking conspicuous posteroventral row of bristles but with a midventral bristle; ventroapical bristle longer than in male and not accompanied by thin hair-like bristles. Male hind tibia flattened and virtually bare ventrally. Female hind tibia simple, nei- 

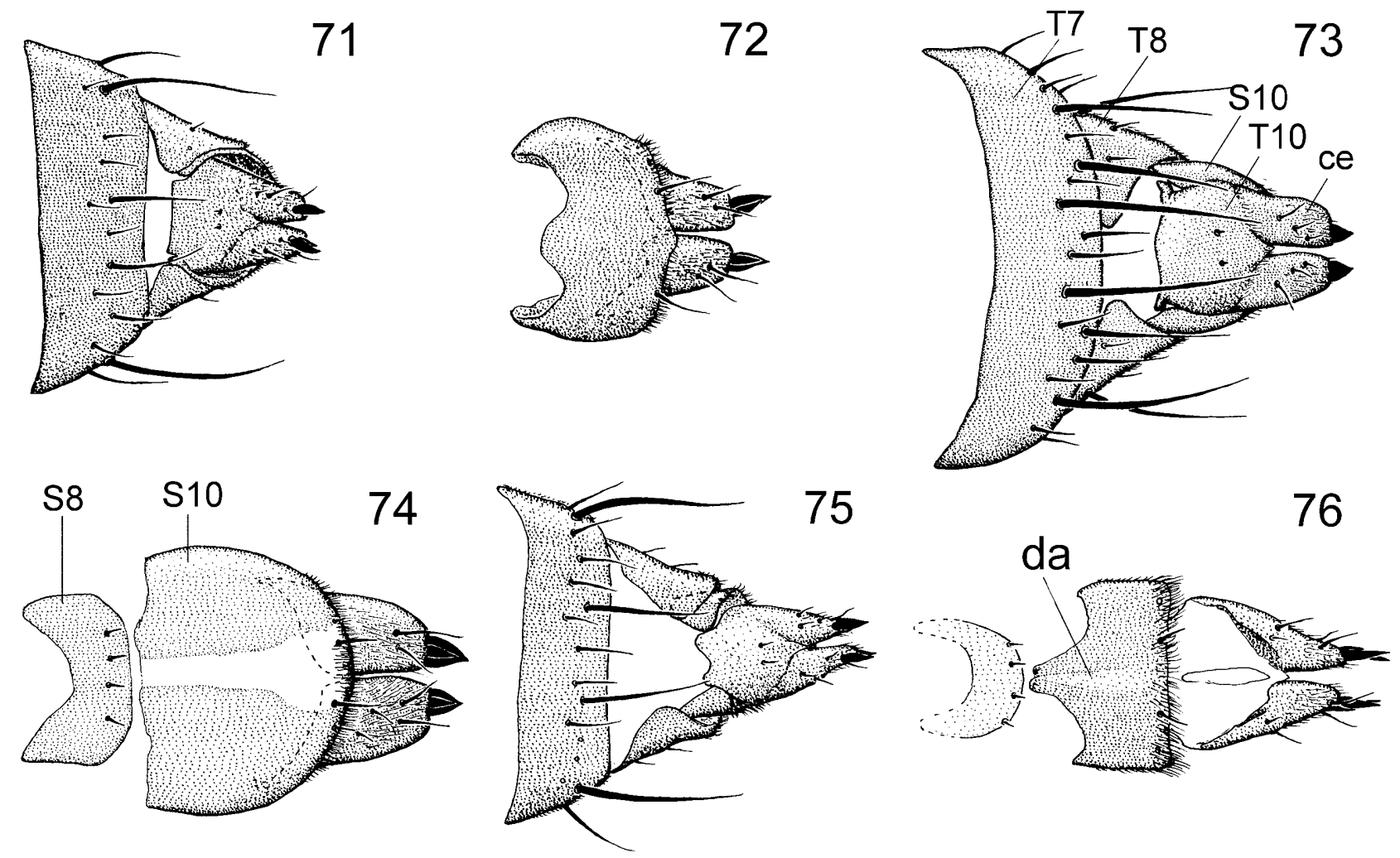

Figs 71-76. Lepidosina females. L. argentinensis sp. n.: 71 - tergite 7 and terminalia, dorsal; 72 - sternite 10 and cerci, ventral. $L$. evanescens sp. n.: 73 - tergite 7 and terminalia, dorsal; 74 - sternites 8,10 and cerci, ventral. L. quadrisquamosa sp. n.: 75 - tergite 7 and terminalia, dorsal; 76 - sternites 8,10 and cerci, ventral (cerci extended). ce - cercus, da - desclerotized area, S - sternite, Ttergite.

ther flattened nor bare ventrally. Second tarsomere of male hind leg swollen and twice as long as basitarsus. Second tarsomere of female hind leg more slender than in male.

Wing with brown costa, other veins relatively pale, more so posteriorly. Third costal sector $0.7 \times$ second. Crossveins $\mathrm{r}-\mathrm{m}$ and $\mathrm{dm}-\mathrm{cu}$ separated by ca. $2.0 \times$ length of $\mathrm{dm}$-cu. Halter, including stem, pale.

Male terminalia (Figs 56-60). Sternite 5 (Fig. 57) with bare disc and with six posterior bristles, middle pair small, outer pairs prominent and scale-like. Synsternite 6-8 (Figs 56, 57) forming a symmetrical ring, dorsal part with broad anterior apodeme projecting anteriorly under tergites 4-5. Genital pouch with a well-developed sclerite (Fig. 59), bearing a field of small denticles on each side. Epandrium (Fig. 58) short dorsally; subanal plate shorter than perianal area, flat on upper part but concave just above cerci. Cerci basally fused and distally contiguous, abruptly tapered to form a very narrow, parallel-sided distal lobe. Surstylus (Fig. 58) bilobed, inner lobe subquadrate; outer lobe narrow, prominently projecting laterally, anterolaterally curved and ending in two closely spaced, large, curved, subequal bristles. Hypandrium (Fig. 60) with short, more or less translucent anterior apodeme. Phallus short and compact (Fig. 60), with basiphallus covering basal $3 / 4$ of dorsal surface of distiphallus. Postgonite (Fig. 60) with nearly circular outline, without posterior projection. Ejaculatory apodeme minute, shieldlike, with two sensory pores.

Female terminalia similar to L. angusticercus, differing as follows (Figs 75, 76, 81): Cerci more slender; large flattened preapical bristle also more slender; microtrichose patch of tergite 10 separated by bare area from lateral and apical microtrichose surfaces of cerci. Intersegmental membrane behind sternite 7 lacking microtrichia. Sternite 8 narrower, only about $0.55 \times$ as wide as sternite 10 , with median pair of setulae near posterior margin only $1.0-1.5 \times$ as far apart as setulae on each side. Sternite 10 divided (Fig. 76), anteroventral margin quite acutely produced forward at middle, medially divided by a distinct desclerotized strip that becomes gradually more obscure posteriorly. Spermathecae $(2+1)$, slightly larger (Fig. 81), single spermatheca ca. $70 \mu \mathrm{m}$ long; surface with fewer transverse ridges than in $L$. angusticercus; individual ducts of paired spermathecae extremely short. In one specimen paired accessory glands were observed as described for L. rutricauda below.

Type material. Holotype $\hat{\delta}$ (DEBU) and 36 paratypes (10 $\hat{\sigma}$, 25 \%). Venezuela. Aragua, El Limón, Pozo del Diablo, $570 \mathrm{~m}$,

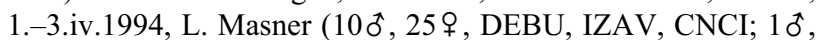
$3 q$ are "Barcode of Life" specimens DEBU0064, 65, 68 and 69).

Other material examined. Venezuela. Aragua, Henry Pittier Natl. Pk., Rancho Grande, 9.iv.1994, L. Masner, 94-05, La Toma, S. S PM. (1 9 , DEBU). 

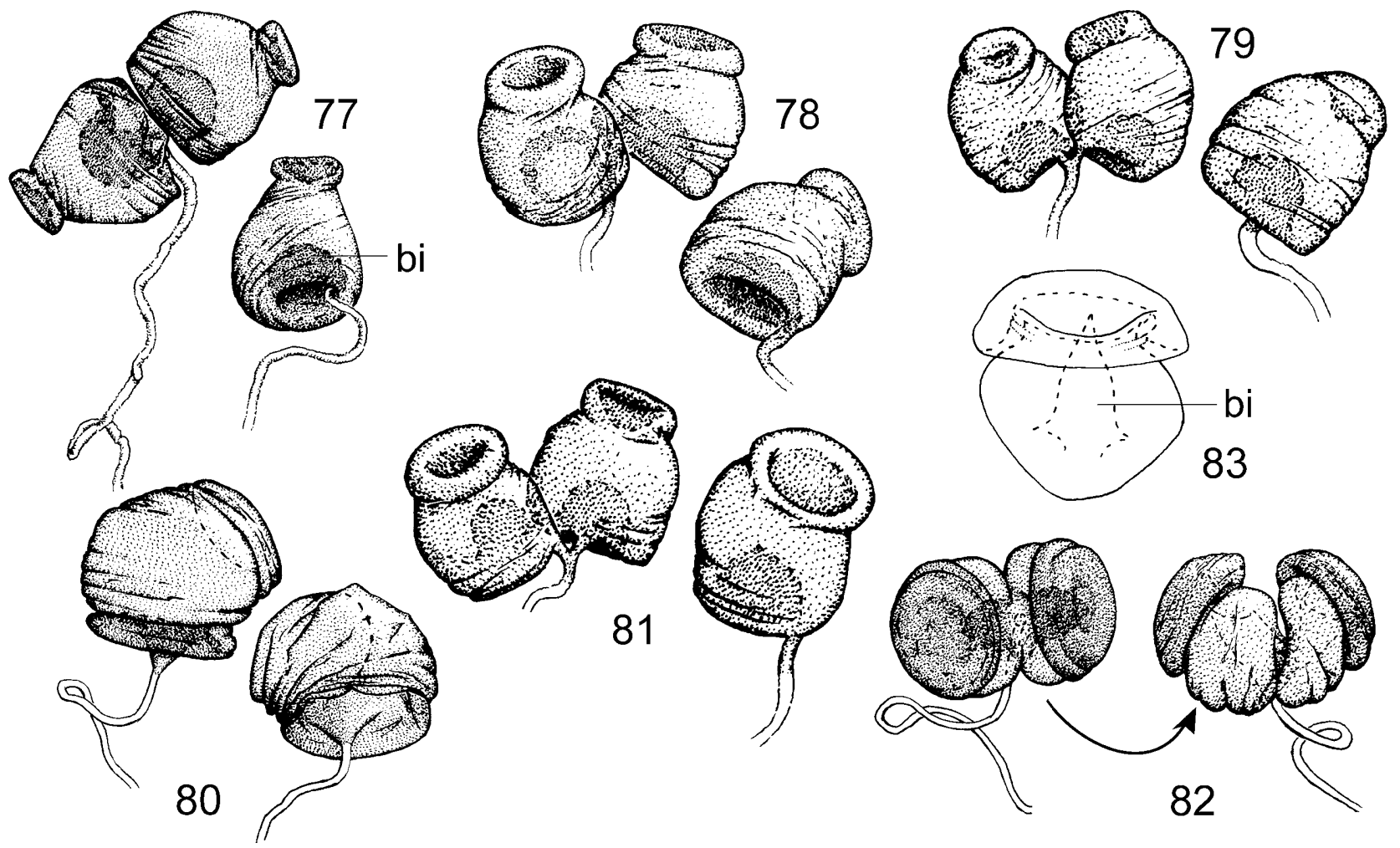

Figs 77-83. Lepidosina spermathecae (not to scale): 77 - L. cubensis sp. n.; 78 - L. argentinensis sp. n.; 79 - L. gibba (Spuler); 80 - L. rutricauda sp. n.; 81 - L. quadrisquamosa sp. n.; 82 - L. evanescens sp. n.; 83 - ditto, schematic, showing basal invagination. bi - basal invagination.

Etymology. The specific epithet refers to the four large scalelike bristles on male sternite 5 .

Distribution. Presently only known from northern Venezuela.

Discussion. Lepidosina quadrisquamosa is very similar to the more widespread Neotropical and Caribbean $L$. angusticercus, differing most obviously in details of the surstylar armature, bristles of the epandrium, male cerci, postgonites and accessory sclerite. The females of these two closely related species differ in spermathecal number, suggesting that a reduction from three to two spermathecae has occurred more than once in the genus.

\section{Lepidosina rutricauda Marshall \& Buck, sp. n.}

(Figs 5, 61-65, 68-70, 80)

\section{Description}

Head mostly black with conspicuous pollinose areas on frons; lower frons reddish; interfrontal bristles in four pairs, middle three pairs larger than lower.

Thorax. Acrostichal bristles in 6-8 rows at level of transverse suture, middle acrostichal bristles slightly to moderately enlarged; prescutellar pair not strongly enlarged. Katepisternal bristles small, posterior one about half as long as fore basitarsus, anterior one extremely small, virtually absent.

Legs. Fore femur with two dorsal to posterodorsal bristles, posteroventral bristles of distal half extremely short in male, slightly longer in female. Fore tibia of male flattened ventrally, lower surface bare basally, sparsely setulose distally; tibia deeply excavated on distal half. Fore tibia of female slender, evenly setulose and not flattened ventrally, distally without anterodorsal emargination. Fore tarsomeres of male conspicuously broad and flat and consecutively shorter (basal tarsomere twice as long as wide, distal tarsomeres slightly wider than long). Mid femur of male with a ventral to posteroventral depression in distal half, ventrobasally with a group of ca. 7 setulae (not in V-shaped formation as in most species), these darker and somewhat stouter than other setulae; posteroventral row of setulae well developed; row arcuate and delineating ventral depression of femur posteriorly; setulae becoming smaller and paler distally. Female mid femur simple, neither with ventral depression nor with conspicuous setulae basally. Male mid tibia curved, ventral surface flat and bare over basal $3 / 4$, very weak rows of anteroventral and posteroventral bristles converging distally towards cluster of preapical bristles; apicoventral bristle short, length not exceeding width of mid basitarsus, accompanied by one long and one mediumsized thin, hair-like bristle. Mid tibia of male with three subequal anterodorsal (proximal, mid, distal) bristles and two very small posterodorsal bristles inserted distal to corresponding anterodorsal bristles (proximal posterodorsal absent or indistinguishable from surrounding setulae on some specimens). Mid tibia of female simple, evenly setulose ventrally and not curved, midventral present, apicoventral bristle long and not accompanied by thin, hair-like bristles; dorsal bristles longer than in male and distal posterodorsal equal to or very slightly longer than distal anterodorsal (in other species posterodorsal 
distinctly longer). Hind tibia of male ventrally flattened and largely bare (except distally where antero- and posteroventral rows of hairs converge), apicoventrally with only short hairs. Female hind tibia simple, evenly setulose ventrally. Second tarsomere of hind tarsus strongly swollen in male, slightly swollen in female.

Wing (Fig. 5) with uniformly pale brown veins, crossveins $\mathrm{r}-\mathrm{m}$ and dm-cu separated by twice length of dm-cu (four times length of $\mathrm{r}-\mathrm{m}$ ). Third costal sector $0.7 \times$ length of second costal sector. Halter stem white, knob brown.

Male terminalia (Figs 61-65). Sternite 5 wider than long (Fig. 62), with evenly setulose disc, posterior margin shallowly emarginate medially, with two pairs of long bristles. Synsternite 6-8 (Figs 61, 62) forming a strong ring, dorsal part with a few inconspicuous bristles at hind margin, with broad anterior apodeme projecting under tergites 4 and 5 (sometimes reaching anterior part of tergite 3); ventral part short, dark, with finger-like, asymmetrical posterior process. Epandrium (Fig. 63) with broad subanal plate continuous with broad and largely fused cerci, combination of subanal plate and cerci forming a concave, scoop-like process; subanal plate with a pair of cruciate bristles, both subanal plate and cerci with paired, short, stout bristles. Basal part of fused cerci with a circular translucent area creating appearance of basally separated but distally fused cerci. Surstylus (Fig. 61) more or less triangular, but only with base and distal face of the triangle pigmented, thus appearing to be divided into a short upper part and an elongatesubquadrate lower part with four long distal bristles and a stout spur at the posteroventral corner. Hypandrium (Figs 64,65 ) unusually robust and dark, with small remnant of anteromedial apodeme, anterolateral surface with striae indicating insertion points of large muscles. Basiphallus extending over posterodorsal surface of phallus (Fig. 64), heavily sclerotized laterally in basal $2 / 3$ (creating impression of two parallel rods in dorsal view) and tapered distally to a pale, spatulate apex extending beyond distiphallus; distiphallus with complex lateral sclerites, ventrally divided into multiple dark, stout teeth; basal teeth shorter; clusters of distal teeth longer. Postgonite pale (Fig. 64), with tapered base and wide, broadly rounded apex. Ejaculatory apodeme not seen, apparently absent.

Female terminalia (Figs 68-70, 80). Tergite 7 same length as tergites 3-6, darker than other tergites, bare on anterior half and with strong posterior bristles including one pair of long posteromedial bristles (the latter longer than in most other species, nearly twice as long as tergite, but not more removed from hind margin than other long bristles; Fig. 68). Tergite 8 with short setulae only, each half strongly sclerotized ventrally. Tergite 10 with relatively large patch of microtrichia; microtrichia unusually long. Cerci more or less truncate apically, with anterior flattened apical bristle very broad, about $3 \times$ as broad as posterior bristle; apical half of dorsal surface of cerci sparsely microtrichose; microtrichose areas of tergite 10 and cerci broadly separated. Transverse microtrichose strip behind sternite 7 separated by unusually short bare area from that sternite. Medial pair of setulae of sternite 8 separated by $3-4 \times$ the distance between setulae on each side. Sternite 10 very large (Fig. 70), ventrally with prominent, dark, incurved apodemes at anterolateral corners; ventral portion between apodemes relatively weakly sclerotized and with gently convex anterior margin; posteroventral margin densely microtrichose. Anteromedial margin of sternite 10 preceded by a transverse, pale brown sclerite (Fig. 70, vaginal sclerite?) that nearly reaches the anterolateral apodemes of sternite 10 in dorsoventral view. Spermathecae $(1+1)$ very large (Fig. 80), length $95-110 \mu \mathrm{m}$, each connected separately by long duct to genital chamber; shape short-cylindrical, long axis bent $45-90^{\circ}$, surface with deep transverse wrinkles; duct inserted on conical base, sclerotized portion of duct very short. Wrinkled elongate accessory glands joining genital chamber close to spermathecal ducts (Fig. 70).

Egg. Slipper-shaped, $0.3 \times$ as wide as long; micropylar processes slightly longer than egg width. Chorion densely granulose, with a secondary dense microgranulosity throughout.

Type material. Holotype of (debu00195148) and 39 paratypes $(26 \hat{0}, 14 \%)$. Ecuador. Napo, Jatun Sacha Reserve, $6 \mathrm{~km} \mathrm{E}$ Misahuallí, $450 \mathrm{~m}, 1^{\circ} 4^{\prime} \mathrm{S}, 7^{\circ} 37^{\prime} \mathrm{W}$, 5.v.2002, varzea, sweep, S.A. Marshall (DEBU). Other paratypes: 1500,43 ㅇ. Ecuador. Same data as holotype, but collected by M. Buck, 2.v.2002 (31 ô, 13 \%, DEBU) and 3.v.2002 (102 $\hat{0}, 25 \%$, DEBU, QCAZ, CNCI; 20 are "Barcode of Life" specimens DEBU0056 and 57); same as holotype but collected by O. Lonsdale, 2.-7.v.2002 $\left(120^{\star}, 3 q, \mathrm{DEBU}\right)$; same as holotype but collected by E.L. Westman, 30.iv.-8.v.2002 (1 $\hat{\sigma}, 2$ \% DEBU); same locality as holotype but 1.-2.v.2002, compost, yellow pans, M. Buck (20, DEBU); Napo, Tena, nr. Hotel Auca, 500 m, 22.-27.v.1987, tall grass/shrubs, Malaise, L.D. Coote \& B.V. Brown, ROM870014 (1 ठै, ROME). Colombia. Leticia, Pepper Farm, 1974, dung trap, V. Nealis ( $1 \hat{\sigma}$, DEBU).

Other material examined. Ecuador. Napo, Tena (11 $q$, DEBU); Napo, SW Puerto Napo, S Limonchicta (1 $9, \mathrm{ROME})$. Peru. Madre de Dios, Manú National Park, Cocha Cashu Biological Station (1 9 , ROME).

Etymology. The specific epithet refers to the scoop-like fused male cerci.

Distribution. Colombia, Ecuador and Peru east of the Andes.

Discussion. Lepidosina rutricauda is the sister species of L. multispinulosa (see discussion of L. multispinulosa). These two species differ markedly from other species in male abdominal characters. The distiphallus is strongly modified to the point where it is difficult to homologize its components with those of other species. The female of L. rutricauda also differs markedly from other species (female of $L$. multispinulosa unknown). The spermathecae are especially unusual because the two spermathecae are on separate long ducts in contrast to other species with only two spermathecae, in which the spermathecae are closely associated on a common duct. The unusually large number of specimens available allowed a more careful study of the internal genitalia than was possible for other species, so it is possible that homologous structures, especially in the female terminalia, have been overlooked in other species. 
ACKNOWLEDGMENTS. We gratefully acknowledge the loan of specimens from the museums listed under Material and methods. R. Hanner (Canadian Barcode of Life Network, University of Guelph) and C. Maitland are thanked for sampling and sequencing the "barcode" region of the COI gene. We also thank R. Langstaff and M. Musial for help with many of the illustrations. This work was funded by NSERC Operating and Discovery grants to the senior author.

\section{REFERENCES}

Malloch J.R. 1914: A partial report on the Borboridae, Phoridae and Agromyzidae. In Cresson E.T. (ed.): Costa Rican Diptera collected by Philip P. Calvert, Ph. D., 1909-1910. Trans. Am. Entomol. Soc. 40: 1-36.

Marshall S.A. 1983: The genus Bromeloecia Spuler in North America (Diptera: Sphaeroceridae). Proc. Entomol. Soc. Wash. 85: 32-35.

Marshall S.A. 1985: A revision of the genus Spelobia Spuler (Diptera: Sphaeroceridae) in North America and Mexico. Trans. Am. Entomol. Soc. 111: 1-101.

Marshall S.A. 1998: A revision of the Archileptocera group, including Anomioptera Schiner, Palaeocoprina Duda and Archileptocera Duda, with a key to sphaerocerid genera with similar wing venation and a description of a new species of Palaeoceroptera Duda (Diptera: Sphaeroceridae). J. Nat. Hist. 32: 173-216.

Marshall S.A. \& CuI Y. 2005: Systematics of Robustagramma, a new genus of New World Sphaeroceridae (Diptera). Zootaxa 1026, 122 pp.

Marshall S.A. \& Langstaff R. 1998: Revision of the New World species of Opacifrons Duda (Diptera, Sphaeroceridae, Limosininae). Contr. Sci. 474, 27 pp.

McAlpine J.F. 1981: 2. Morphology and terminology - adults. In McAlpine J.F., Peterson B.V., Shewell G.E., Teskey H.J., Vockeroth J.R. \& Wood D.M. (eds): Manual of Nearctic Diptera. Vol. 1. Monograph 27, Research Branch, Agriculture Canada, Ottawa, pp. 9-63.
Richards O.W. 1967: 72. Family Sphaeroceridae (Borboridae). In Vanzolini E.P. \& Papavero N. (eds): A Catalogue of the Diptera of the Americas South of the United States. Vol. 72. Departamento de Zoologia, Secretaria da Agricultura, São Paulo, 28 pp.

RоHÁČEK J. 1982: Revision of the subgenus Leptocera (s. str.) of Europe (Diptera, Sphaeroceridae). Entomol. Abh. Staat. Mus. Tierk. Dresden 46: 1-44.

RонÁČEK J. 1983a: A monograph and re-classification of the previous genus Limosina Macquart (Diptera, Sphaeroceridae) of Europe. Part II. Beitr. Entomol. 33: 3-195.

RонÁĆEK J. 1983b: A monograph and re-classification of the previous genus Limosina Macquart (Diptera, Sphaeroceridae) of Europe. Part III. Beitr. Entomol. 33: 203-255.

RонÁČ́E J. 1985: A monograph and re-classification of the previous genus Limosina Macquart (Diptera, Sphaeroceridae) of Europe. Part IV. Beitr. Entomol. 35: 101-179.

RоHÁĆEK J. 1991: A monograph of Leptocera (Rachispoda Lioy) of the West Palaearctic area (Diptera, Sphaeroceridae). Čas. Slez. Muz. Opava (A) 40: 97-288.

ROHÁČEK J. \& PAPP L. 1988: A review of the genus Paralimosina L. Papp (Diptera, Sphaeroceridae), with descriptions of ten new species. Ann. Hist.-Nat. Mus. Natn. Hung. 80: 105-143.

Smith M.A., Woodley N.E., Janzen D.H., Hallwachs W. \& Hebert P.D.N. 2006: DNA barcodes reveal cryptic hostspecificity within the presumed polyphagous members of a genus of parasitoid flies (Diptera: Tachinidae). Proc. Natl. Acad. Sci. USA 103: 3657-3662.

Spuler A. 1925: North American species of the subgenus Scotophilella Duda (Diptera, Borboridae). J. N. Y. Entomol. Soc. 33: 70-84, 147-162.

SwOFFord D.L. 2001: PAUP*: Phylogenetic Analysis Using Parsimony (*and Other Methods), Version 4.0b10 for 32-bit Microsoft Windows. Sinauer Associates Inc., Sunderland, Mass.

Received January 24, 2007; revised and accepted April 30, 2007 